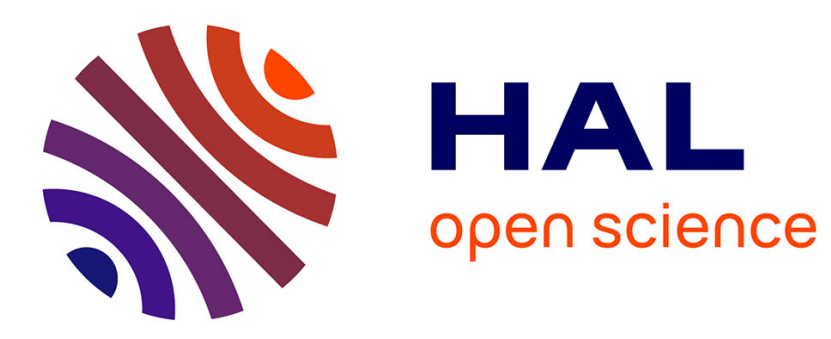

\title{
Effect of fretting wear on crack initiation for cylinder-plate and punch-plane tests
}

S. Basseville, M. Niass, D. Missoum-Benziane, J. Leroux, G. Cailletaud

\section{To cite this version:}

S. Basseville, M. Niass, D. Missoum-Benziane, J. Leroux, G. Cailletaud. Effect of fretting wear on crack initiation for cylinder-plate and punch-plane tests. Wear, 2019, 420, pp.133 - 148. 10.1016/j.wear.2018.12.059 . hal-03486915

\section{HAL Id: hal-03486915 https://hal.science/hal-03486915}

Submitted on 20 Dec 2021

HAL is a multi-disciplinary open access archive for the deposit and dissemination of scientific research documents, whether they are published or not. The documents may come from teaching and research institutions in France or abroad, or from public or private research centers.
L'archive ouverte pluridisciplinaire HAL, est destinée au dépôt et à la diffusion de documents scientifiques de niveau recherche, publiés ou non, émanant des établissements d'enseignement et de recherche français ou étrangers, des laboratoires publics ou privés.

\section{(ㄷ)(1) $\$$}

Distributed under a Creative Commons Attribution - NonCommerciall 4.0 International 


\title{
Effect of fretting wear on crack initiation for cylinder-plate and punch-plane tests
}

\author{
S. Basseville ${ }^{*, a, b}$, M. Niass ${ }^{\mathrm{b}}$, D. Missoum-Benziane ${ }^{\mathrm{b}}$, J.Leroux $^{\mathrm{c}}$, G. Cailletaud $^{\mathrm{b}}$ \\ ${ }^{a}$ Université de Versailles Saint-Quentin, 45 avenue des Etats-Unis, 78000 Versailles, France \\ ${ }^{b}$ MINES ParisTech, Centre des Matériaux, CNRS UMR 7633, BP 8791003 Evry Cedex, France \\ ${ }^{c}$ Safran Aircraft Engines, Rond-point René Ravaud, 77550 Moissy-Cramaye, France
}

\begin{abstract}
Numerous studies highlighted the influence of the fretting sliding conditions on fretting damage. Gross slip may lead to material removal while partial slip conditions favor crack initiation and propagation. The aim of this work is to develop a robust computational framework for fretting simulation in both regimes including both wear and fatigue-crack initiation. This framework involves the resolution of the contact problem, damage accumulation, update of the geometry and automatic remeshing to capture the material removal. A detailed description of the employed wear and damage models is presented; the competition of the two corresponding mechanisms determine weather the damaged zones are worn out or weather a fatigue cracks are initiated. The wear model is based on a non-local wear criterion making a link between friction energy density and the local wear depth, which enables to update the surface profile for the following calculation step. A Smith-Watson-Topper (SWT) parameter combined with a linear cumulative law allows to predict the crack-nucleation risk. The selected material under study is a classical titanium alloy, Ti-6Al-4V. A series of numerical simulations is carried out to study the influence of surface wear on fretting damage distribution under different slip regimes for two contact geometries : a cylinder-on-plane and a punch-on-plane. Our numerical results enable us to distinguish various damage mechanisms and are in a very good agreement with experimental data taken from the literature.
\end{abstract}

Key words: fretting; wear; fatigue crack initiation; damage ; finite element simulation; titanium alloy

\section{Introduction}

Fretting denotes a tribological phenomenon related to motion of small amplitudes between two contact surfaces, it is observed in many mechanical assemblies subjected to vibration,

\footnotetext{
*. Corresponding author

Email addresses: stephanie.basseville@uvsq.fr (S. Basseville), maimouna.niass@mines-paristech.fr (M. Niass), djamel.missoum-benziane@mines-paristech.fr (M. Niass), julien.leroux@safrangroup.com (J.Leroux), georges.cailletaud@mines-paristech.fr (G. Cailletaud)
} 
such as rivets, turbine blade fixings, shafts, steam generator, etc. Microsliding generates nearsurface material degradations and can affect the reliability and durability of the structures subjected to fretting.

Fretting can be classified into two different sliding conditions, depending on the displacement amplitude : the partial slip regime (smaller amplitude) and the gross sliding regime (larger amplitude). In the partial slip condition, the contact area is divided in a near-contactedge slip zone and an inner stick zone. The evolution of tangential force versus displacement in this case represents a closed elliptical loop which corresponds to a low friction dissipation. This low dissipation explains why the main outcome of fretting damage is the crack nucleation. In contrast, under gross sliding condition, the whole contact surface is subjected to frictional sliding. The fretting hysteresis loop is large and induces significant friction dissipation. The surface wear is the dominant deterioration mechanism, it prevents the nucleation and extension of fatigue cracks.

The concept of fretting maps, already mentioned earlier in the eighties [1], has been introduced by [2], [3] to underline the relation between transition from partial slip to gross slip and the transition from crack initiation to wear. These transitions are described in terms of applied vertical force $P$ and tangential displacement $\delta^{*}$. Four domains shall be observed (Fig.1) :

- Under partial slip,

- there is no damage (I), for a small displacement amplitude;

- cracks (II) can nucleate and propagate for a larger displacement amplitude.

- Under gross slip,

- there may be a competition between fatigue cracking and wear (III)

- or wear only $(I V)$.

There is a lot of damage and wear models in the literature. However, fretting wear studies are traditionally performed using a modified version of the classical Archard law. The global Archard approach allows to estimate the wear volume [4]. The local interpretation of Archard's law is based on the local accumulated friction-dissipated energy in the interface, which permits to evaluate the local amount of wear [5]. Numerical simulations are then used to follow the evolution of contact-geometry during the fretting test. After every fretting cycle the surface geometry can be updated in accordance with the energy-based local Archard's law. Several techniques to update the worn profiles exist :

- by modifying the contact algorithm used in case of contact between two bodies. This method consits in changing the gap function during the load sequence [6].

- by a simple displacement of nodes of the mesh in the direction colliner with the initial normal vector in order to capture the local wear depth; the under-surface nodes are also displacement to keep an appropriate aspect ratio of finite elements, [5, 7].

- by a displacement of surface nodes only and a remeshing of the volume [8].

As for the fretting fatigue, multi-axial fatigue criteria are widely used to predict the crack nucleation and to estimate the lifetime. Two types of fatigue models are proposed : (1) purely stress depend models, which use high cycle fatigue criteria, as Dang Van's approach for infinite endurance conditions, and (2) mixed strain-stress fatigue models such as SmithWatson-Topper (SWT) criteria for low cycle fatigue $[9,10,8]$. The wear process may also 


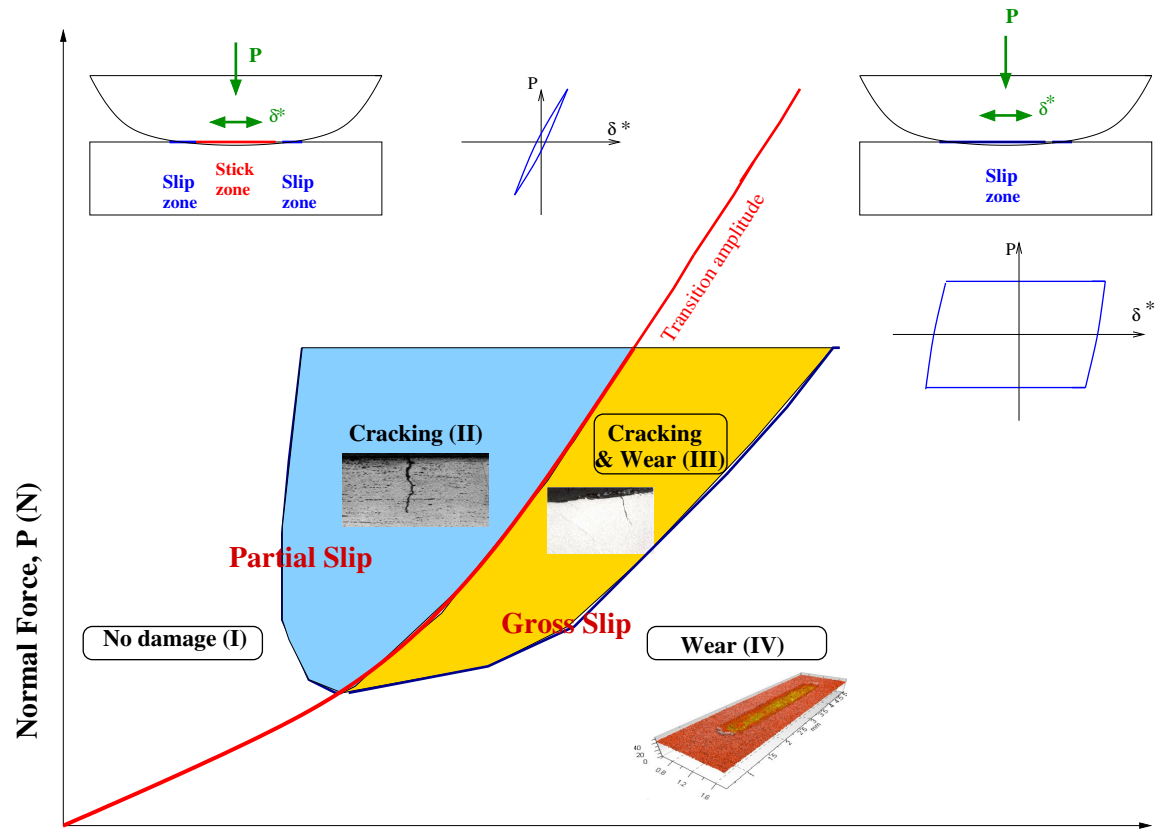

Displacement amplitude, $\delta^{*}$ (micron)

FiguRE 1: Illustration of the fretting map. Description of the fretting damage according to the fretting conditions.

be combined with damage accumulation by means of a linear Miner's cumulative damage law as it was done in the following studies for specific geometries and loading conditions $[11,10,12,13]$. In most of classical studies, the degradation mechanisms (wear and cracking) are treated separately. Prediction of crack nucleation is analyzed, according to initial contact geometries, without any surface update due to wear [14, 15]. Fretting wear simulations are used to provide a worn surface evolution of the interface, in agreement with experimental data without crack nucleation $[6,16,17,18,7]$. Nevertheless, some recent studies successfully take into account both effects : crack nucleation and the evolution of the contact surfaces under partial and/or total slip regimes $[19,8,10,12]$.

The originality of the present paper is to propose a robust computational framework to simulate the fretting for arbitrary geometry and accounting both for wear and fatigue crack initiation. The novelty also includes (1) a non-local wear criterium, which is defined from a local dissipated friction-energy density, and a new concept of "cycle accelerator" enabling a faster and robust simulation of millions of cycles.

The crucial point of these simulations is to be able to reproduce faithfully the wear mechanisms, such as the abrasive wear under gross slip regime or the abrasive/adhesive wear under partial slip regime, as experimentally observed. A particular attention is paid to the influence of surface wear on fretting damage redistribution.

The paper is organized as follows : The second section describes the strategy of the simulation. The wear model and the mesh update procedure are introduced in Section 3. 
The analysis of the fatigue process is described in Section 4. To illustrate the performance of the developed algorithms and employed model in fretting test, two contact geometries are selected and presented in Section 5. Finally, Section 6 is devoted to the analysis of the obtained results. 


\section{Nomenclature}

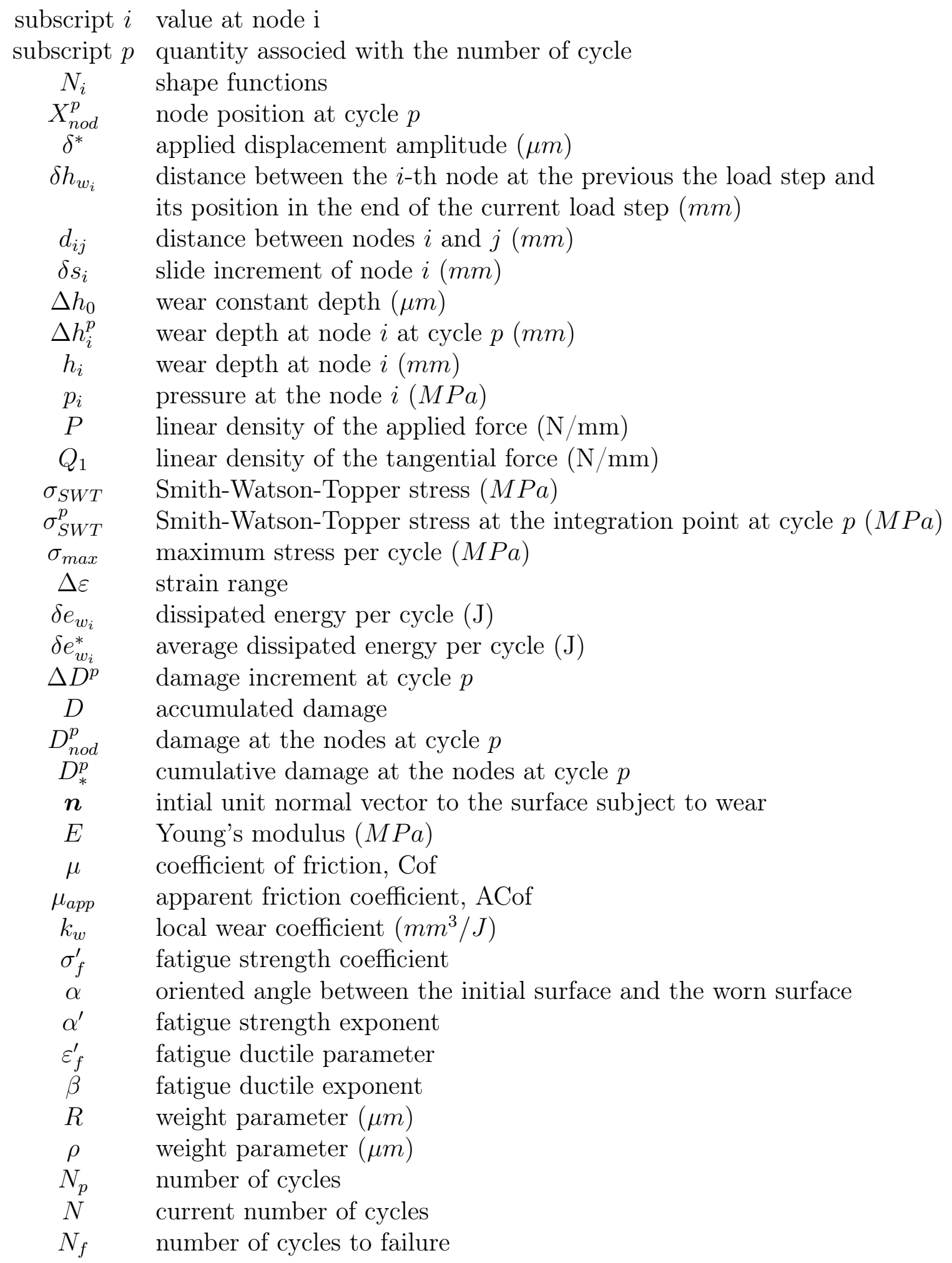




\section{Strategy of the simulation process}

Wear and damage computation is introduced in the finite element code ZSet/ZéBuLon [20]. The numerical wear process consists in mesh updating after each fretting cycle. The contact is modelled by an impactor/target technique, and is solved by a classical flexibility method with node-to-segment discretization [21, 22]. The friction behavior between elastic contacting bodies is governed by the Coulomb's law. Only one of surfaces undergoes the wear process, i.e. the wear process is unilateral. In master/slave separation of surfaces in node-to-segment contact discretization, on purpose we select the slave surface the one that is subjected to wear. By slave surface we mean the surface that possesses nodes, whereas the master surface is defined by edges of finite elements [23].

The wear model is a non-local version [8] of the classical Archard law, where wear depth follows from the surface energy density averaged in vicinity of every point. To simulate the change of geometry on the slave surface, its nodes are shifted by the distance proportional to the dissipated energy in the direction collinear with the normal to the intact and undeformed slave surface. The updated finite element mesh is built using gmsh mesh generator [24] (Fig.4). Implementation of the method is described in Section 3.

Simultaneously, the Smith-Watson-Topper (SWT) parameter, combined with a linear cumulative law, allows to predict the crack-nucleation risk. After each numerical fretting cycle, an equivalent stress is computed at each integration point under the plane contact area, then compared to a fatigue limit (Section 4.1). Afterwards, the damage accumulation is evaluated by a linear Miner's law at each node, under the plane contact area, which requires a field transfer (Section 4.2).

The strategy of the simulation process is illustrated by the flowchart of Fig.2.

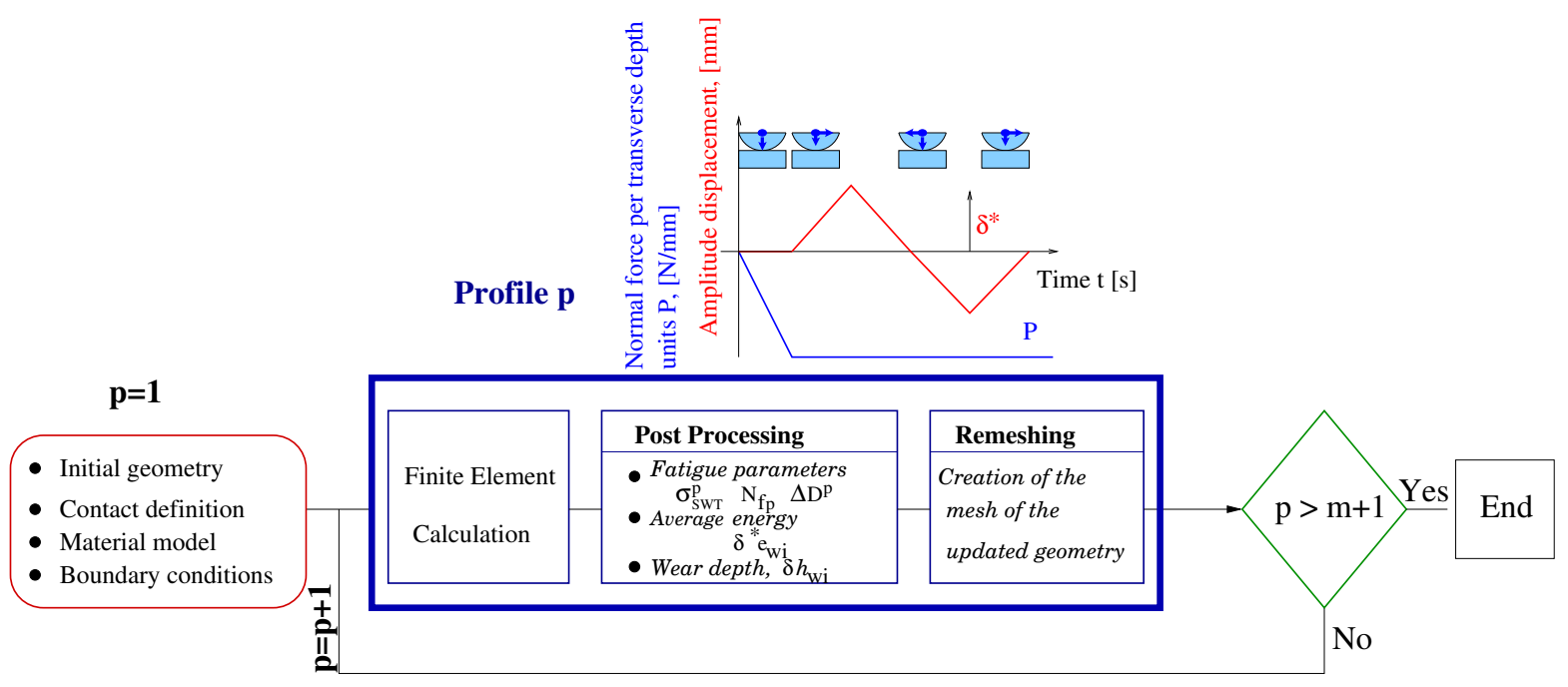

FIGURE 2: Flowchart illustrating the FE-based incremental simulation methodology of wear. 


\section{Wear model}

For each new profile defined after each wear cycle, the nodes $i$ of the impactor surface are moved according to :

$$
\delta \boldsymbol{h}_{w_{i}}=-k_{w} \delta^{*} e_{w_{i}} \boldsymbol{n}
$$

where $\delta h_{w_{i}}$ is the increment of wear depth (a vector collinear with the normal $\boldsymbol{n}$, which is assumed to be perpendicular to the intact and undeformed slave surface), $k_{w}$ is the local wear coefficient, $\delta^{*} e_{w_{i}}$ the non-local average dissipated energy of the $i$-th node defined by

$$
\delta^{*} e_{w_{i}}=\frac{\sum_{d_{i j}<R} \delta e_{w_{i}} \exp \left(-\left(d_{i j} / \rho\right)^{2}\right)}{\sum_{d_{i j}<R} \exp \left(-\left(d_{i j} / \rho\right)^{2}\right)},
$$

where $d_{i j}$ is the distance between the node $i$ and the node $j$, averaging radius $R$ and decay distance $\rho$ are the averaging parameters optimized to maintain stable and smooth calculation of surface energy density, and therefore ensuring smooth wear profiles ${ }^{1}, \delta e_{w_{i}}$ is the local dissipated energy during one cycle defined by $\delta e_{w_{i}}=\mu \sum_{k} p_{i}^{t} \delta s_{i}^{k}$, where $p_{i}^{k}$ is the pressure computed at node $i$ at time step $k, \delta s_{i}^{k}$ is the slide increment of node $i$ at time increment $k$, and $\mu$ the friction coefficient; the sum is over all time increments $k$ forming a single fretting cycle.

The classical strategy assumes that a certain number of cycles, $N_{p}$, can be simulated with fixed worn geometry, so the surface is updated after $N_{p}$ cycles [10] by increment :

$$
\delta \boldsymbol{h}_{w_{i}}=-N_{p} k_{w} \delta^{*} e_{w_{i}} \boldsymbol{n}
$$

The total number of cycles is then computed as :

$$
N=\sum_{p=1}^{m} N_{p}
$$

and the accumulated wear at node $i$ writes :

$$
h_{i}=\sum_{p=1}^{m} \Delta h_{i}^{p}
$$

This strategy requires to optimize the parameter $N_{p}$ to maintain stable and continuous surface change [25]. An alternative method introduces a control in terms of wear depth $\Delta h_{0}$ for all cycles. The number of needed cycles to reach the wear depth increment $\Delta h_{0}$ will decrease during the wear process. This can be evaluated as :

$$
N_{p}=\min _{i}\left(\Delta h_{0} / \delta h_{i}\right)
$$

1. The analysis of these parameters is presented in A. 
The total number $N$ of experimental fretting cycles is then equal to the sum of the experimental cycles $N_{p}$. After $m$ numerical fretting cycles, the cumulative wear at node $i$ is given by :

$$
h_{i}=\left(\sum_{p=1}^{m} N_{p}\right) \Delta h_{0}
$$

This process allows to determine the number of numerical fretting cycles required to obtain a given wear depth.

Figure 3 illustrates the two numerical wear procedures. The profiles marked with blue crosses are obtained with a suite of blocks of $N_{p}$ cycles, while the profiles marked with a red line are obtained with a constant wear depth $\Delta h_{0}$ for each block.

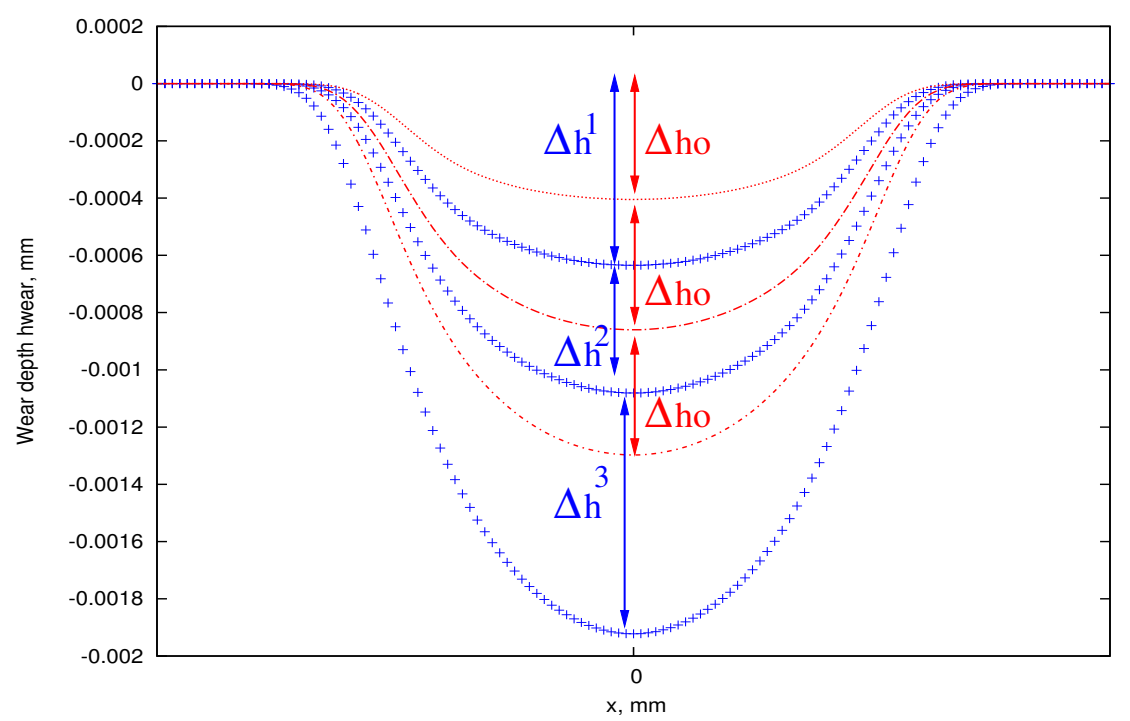

FigURE 3: Three successive wear profiles with a given number of cycles between profiles $\left(\Delta h^{1}, \Delta h^{2}, \Delta h^{3}\right)$ or a constant erosion depth $\left(\Delta h_{0}, \Delta h_{0}, \Delta h_{0}\right)$.

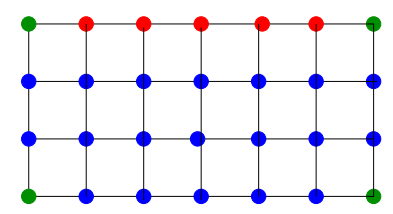

(p)th mesh

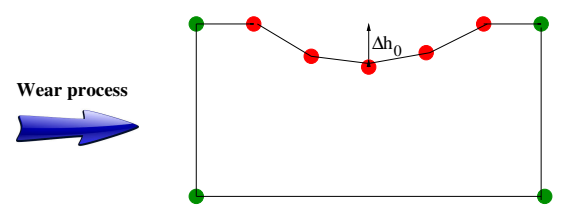

(p)th update of the worn geometry

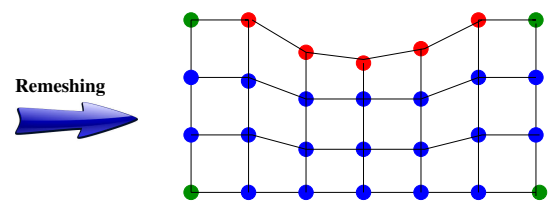

$(p+1)$ th construction of the worn mesh

- Nodes required for the description of the geometry plan

- Impactor nodes moving in the normal direction

- Nodes created by the mesh generator

FIGURE 4: Illustration of the wear process : update of the worn geometry and construction of the worn mesh. 
In summary, for each profile, wear is represented by a vertical translation of each node on the contact surface in the normal direction to the initial surface. The erosion is proportional to the average surface energy density $\delta^{*} e_{w_{i}}$. At the end of the wear process, an updated geometry of the impactor surface is determined, a new mesh of which is generated. All internal elements are updated, in order to ensure a good quality mesh. Figure 4 illustrates this process. Wear "episodes" are repeated, until the target wear depth is reached.

\section{Damage model}

\subsection{The SWT multiaxial fatigue criterion}

The classical Smith-Watson-Topper (SWT) criterion [26] is considered to asses fatigue damage. The effective stress $\sigma_{S W T}$ is a function of the maximum stress in the cycle and the strain range :

$$
\sigma_{S W T}=\sqrt{E \sigma_{\max } \frac{\Delta \varepsilon}{2}}
$$

The number of cycles to failure $N_{f}$ is then can be found from the following equation :

$$
\frac{\sigma_{S W T}^{2}}{E}=\frac{{\sigma_{f}^{\prime}}^{2}}{E}\left(2 N_{f}\right)^{2 \alpha^{\prime}}+\sigma_{f}^{\prime} \varepsilon_{f}^{\prime}\left(2 N_{f}\right)^{\alpha^{\prime}+\beta}
$$

where material parameters $\sigma_{f}^{\prime}$ and $\alpha^{\prime}$ (respectively $\varepsilon_{f}^{\prime}$ and $\beta$ ) are the fatigue strengh (respectively the fatigue ductile coefficient and exponent), and $E$ is the Young's modulus. The equivalent stress $\sigma_{S W T}$ is compared at the integration points for each profile to the fatigue limit $\sigma_{0}^{*}$ in pure tension.

\subsection{Damage accumulation}

The fatigue damage accumulation is taken into account by means of a linear Miner's law. For the $p^{t h}$ profile, the damage increment $\Delta D^{p}$ is therefore expressed by :

$$
\Delta D^{p}=\frac{N_{p}}{N_{f p}}
$$

where $N_{p}$ is the number of cycles determined by the expression (3) and $N_{f p}$ the number of cycles to failure obtained with the SWT criterion relation (5). Thus, after $m$ numerical fretting cycles, the accumulated damage is expressed by :

$$
D=\sum_{p=1}^{m} \Delta D^{p}
$$

Crack nucleation occurs when $D$ reaches 1 .

For each profile, the field of SWT stress is computed at the integration points, meanwhile damage accumulation is evaluated at nodes, so that a field transfer has to be applied, according to the following procedure :

- Step 0 of the procedure assumes that the actual damage $D_{n o d}^{p}$ is known at nodes for the $p^{\text {th }}$ profile. 
Step 0

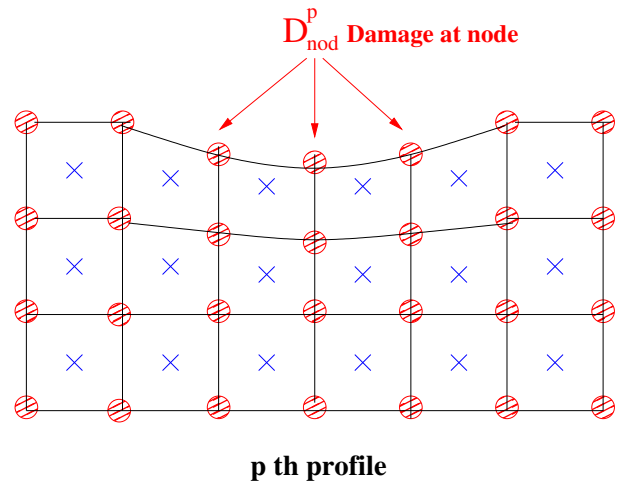

Step 3 Mapping of $D_{\text {nod }}^{p}$ to $(p+1)$ th mesh and

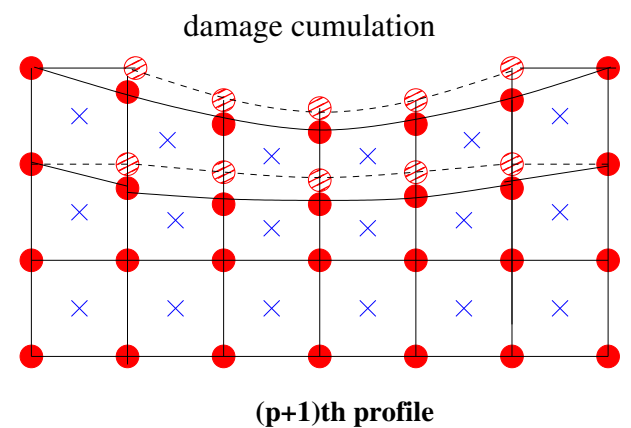

$(\mathbf{p}+1)$ th profile
Step 1 Finite Element resolution compute
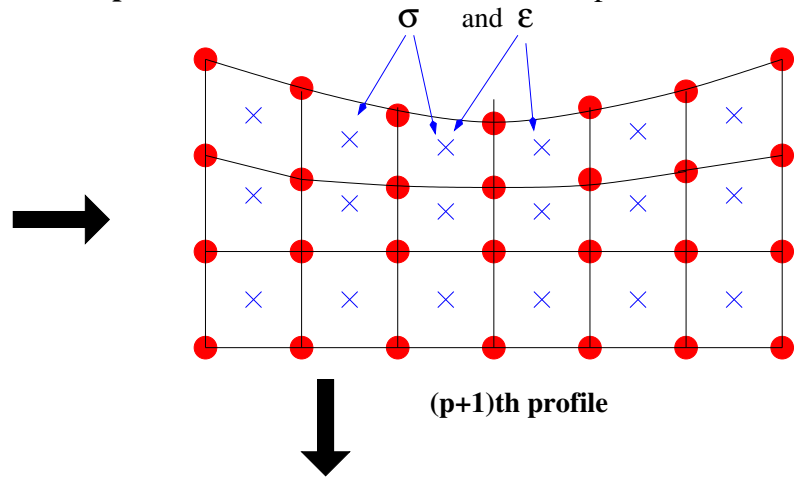

Step 2 Post-processing to compute $\sigma_{\text {SWT }}^{\mathrm{p}+1}$ and $\Delta \mathrm{D}^{\mathrm{p}+1}$

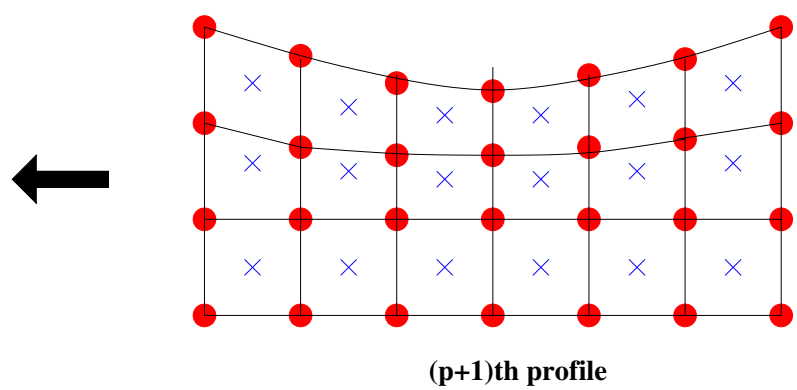

Nodes $\times$ Integration Point

FiguRE 5: Illustration of the field transfer methodology applied to fatigue damage. Step 0 : Damage $D_{\text {nod }}^{p}$ for the $p^{t h}$ profile. Step 1 : Calculation of the stress and strain fields on $(p+1)^{t h}$ mesh. Step 2 : Evaluation of $\sigma_{S W T}^{p+1}$ and of damage increment $\Delta D^{p+1}$ for the $(p+1)^{t h}$ profile. Step 3 : Field transfer to map $D_{\text {nod }}^{p}$ to $(p+1)^{t h}$ mesh and cumulation with damages $D_{\text {nod }}^{p+1}$ for the $(p+1)^{\text {th }}$ profile.

- Step 1 corresponds to the FE resolution on mesh $(\mathrm{p}+1)$ to compute the stress and strain fieds.

- At step 2, the equivalent SWT stress $\sigma_{S W T}^{p+1}$ is computed at the integration points, then extrapolated to the nodes. The number of cycles to failure $N_{f_{p+1}}$ is then known, allowing to compute the damage increment $\Delta D^{p+1}$ at nodes for the $(p+1)^{t h}$ profile.

- In step 3, the damage value $D_{n o d}^{p}$ is transferred to the $(p+1)$ mesh nodes and added to $\Delta D^{p+1}$ in order to determine the damage accumulation. The technique is based on an interpolation by means of the shape functions $N_{i}$. The next node position $X_{n o d}^{p+1}$ is located in the $p_{-}$mesh and the updated cumulative damage $D_{*}^{p+1}$ is computed by interpolation at the position $X_{n o d}^{p+1}$ by the following relation using the shape functions $N_{i}$

$$
D_{*}^{p+1}=\sum N_{i}\left(X_{\text {nod }}^{p+1}\right) D_{\text {nod }}^{p}
$$


Thus, after the $(\mathrm{p}+1)^{t h}$ fretting cycle, the actual damage $D_{\text {nod }}^{p+1}$ at the mesh nodes of the plane is computed by the following relation

$$
D_{n o d}^{p+1}=D_{*}^{p+1}+\Delta D^{p+1}
$$

\section{Finite element model}

\subsection{FE mesh and boundary conditions}

A 2D plane strain FE model is considered with two contact cases : a cylinder-on-plate $(\mathrm{C} / \mathrm{P})$ and a punch-on-plane $(\mathrm{P} / \mathrm{P})$. Both geometries are represented in Fig.6. The cylinder has a radius of $10 \mathrm{~mm}$, that is consistent with the data of the fretting map [27]. The punch has a flat surface of $3 \mathrm{~mm}$ and a curvature radius of $1.35 \mathrm{~mm}$ at each corner. A free mesh made of plane strain 3-node linear elements is used. To combine a good precision with reasonable computation time, the mesh is refined towards the contact area, meanwhile far from the contact zone, the element size gradually increases. The element size in the contact zone is mentioned in Fig.6.

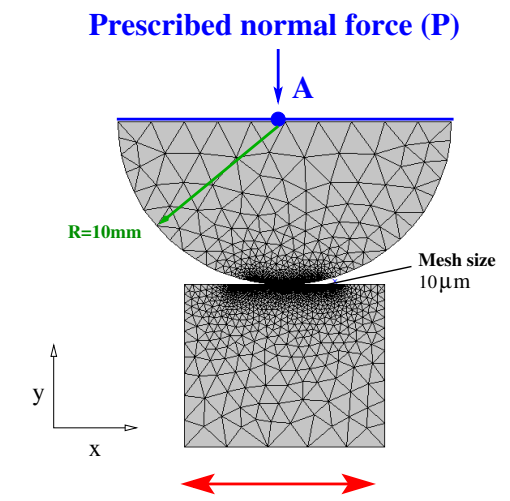

Prescribed horizontal displacement $\delta^{*}$

(a)

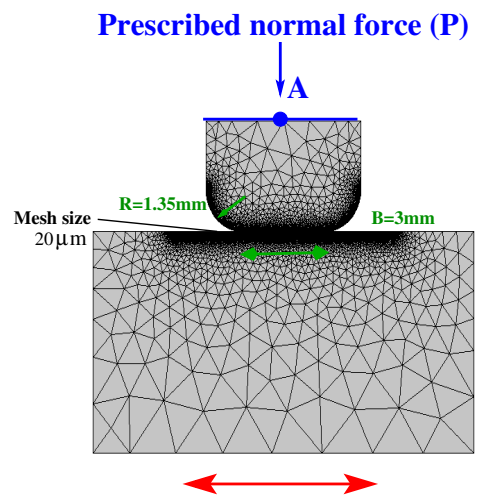

Prescribed horizontal displacement $\delta$ *

(b)

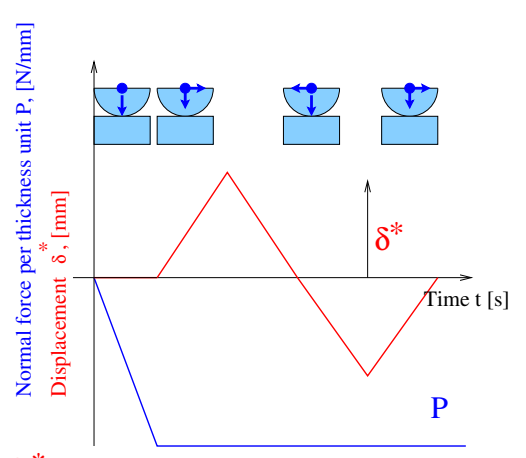

(c)

Figure 6: (a) Initial FE mesh of a 2D cylinder-plate contact model, (b) Initial FE mesh of a 2D punch-plate contact model (c) Boundary conditions.

Figure 6.c illustrates the loading history modelled to simulate the fretting cycle. The boundary conditions are applied in two steps. First, a constant normal load per transverse width units $P$ is imposed at point A on the top of the half cylinder or on the top of the punch. All the nodes of the upper diameter of the circle or the upper of the punch are constrained to have the same vertical displacement via a multi-point constraint condition. The plate is kept fixed by locking its bottom and side nodes. Second, a periodic horizontal cyclic displacement of amplitude $\delta^{*}$ is applied to the bottom and side nodes of the plate. For each profile, a new mesh taking into account the erosion of the plate is generated (Section 3) and the loading is applied similarly for the next cycle.

For the cylinder-on-plate, the conditions are selected in the fretting maps from the literature [27], and correspond to the four domains : 
- A normal force per transerve width units of $133 \mathrm{~N} / \mathrm{mm}$ and a low displacement amplitude of $5 \mu \mathrm{m}$ correspond to no damage regime;

- A normal force per transverse width units of $300 \mathrm{~N} / \mathrm{mm}$ and a low displacement amplitude of $10 \mu \mathrm{m}$ corresponds to the fatigue-predominant regime;

- A normal force per transverse width units of $300 \mathrm{~N} / \mathrm{mm}$ and an intermediate displacement amplitude of $25 \mu \mathrm{m}$ corresponds to the regime of competition between cracking and wear;

- A normal force per transverse width units of $300 \mathrm{~N} / \mathrm{mm}$ and a large displacement amplitude of $100 \mu \mathrm{m}$ corresponds to the wear regime.

For the punch-plate model, the conditions correspond to a mechanical response in partial slip or gross slip conditions. These conditions are :

- A normal force per transerve width units of $2470 \mathrm{~N} / \mathrm{mm}$ and a low displacement amplitude of $50 \mu \mathrm{m}$ correspond to the regime where fatigue is predominant;

- A normal force per transerve width units of $2470 \mathrm{~N} / \mathrm{mm}$ and a large displacement amplitude of $150 \mu \mathrm{m}$ corresponds to the wear regime.

The set of loading conditions are summarized in Table 1.

\begin{tabular}{|l|l|c|c|c|c|}
\hline & & No damage & Cracking & Cracking/Wear & Wear \\
\hline Cylinder & $P(N / m m)$ & 133 & 300 & 300 & 300 \\
Plate & $\delta^{*}(\mu \mathrm{m})$ & 5 & 10 & 25 & 100 \\
\hline Punch & $P(N / m m)$ & -- & 2470 & -- & 2470 \\
Plate & $\delta^{*}(\mu m)$ & -- & 50 & -- & 150 \\
\hline
\end{tabular}

TABLE 1: Loading conditions for the two geometries.

\subsection{Material parameters}

The specimens, cylinder and plane or punch and plane, are made of of Ti-6Al-4V alloy. The Young's modulus is $119 \mathrm{GPa}$ and the Poisson's ratio 0.3.

The value of the friction coefficient $(\mathrm{CoF})$ is still an open problem in the literature. It may depend on many factors (normal load, stroke, material compositions, initial lubrification, etc). It might typically start from low values, like 0.3 , then increase during the tests, and reach values of 1 or even higher within the first few thousand cycles [28]. In our simulations, the friction coefficient of 0.8 is used to represent the average value of a dry Ti6Al4V-Ti6Al4V contact, as measured in the experimental tests $[28,29]$. The wear parameter is not steady during fretting test and depends on the fretting conditions (contact load, sliding amplitude and number of fretting cycles). An average value of $k_{w}=1.43 \times 10^{-5} \mathrm{~m}^{3} / \mathrm{J}$ is representative of the studied fretting contact pair [10]. 


\section{Results and discussion}

Foremost, the numerical tools to describe the fatigue damage and the wear during the fretting test must be validated. Thus, several simulations are carried out on two contact geometries $(\mathrm{C} / \mathrm{P}$ and $\mathrm{P} / \mathrm{P})$ with a plane strain $\mathrm{FE}$ model. For each simulation, the numerical loops, the wear profile and, the fatigue damage are analyzed and compared with the experimental data.

\subsection{Slip regimes}

The curves of column A in Fig.8 represent the numerical tangential force-displacement loops with different loading conditions selected in the fretting maps [27], for a cylinder-plate configuration at beginning of the test and for several eroded profiles. For the partial slip regime, the loops show a small hysteresis, see Fig. 8.A.a and 8.A.b. In contrast, gross sliding conditions provide a large hysteresis with a parallelogram shape, (Fig. 8.A.c and 8.A.d.). The part of the loop corresponding to the sliding period is horizontal, then becomes tilted for eroded profiles during the fretting cycles. The evolution of the fretting loops follows from the change of the contact geometry, which leads to the emergence of an apparent friction coefficient $\left(\mu_{\text {app }}\right)$ defined by

$$
\mu_{\text {app }}=\frac{\mu+\tan (\alpha)}{1-\tan (\alpha)}
$$

where $\alpha$ is the oriented angle between the initial surface and the tangent of the worn surface. The calculation of $\mu_{a p p}$ is detailed in $\mathrm{B}$.

During the fretting test, the simulated loops capture the evolution observed in the experimental tests, see $[16,30,31,10,32]$. This is enough to compare the numerical results to experimentally measured tangential force-displacement loops for different load combinations during a fretting test performed in [30], Fig 7 . The authors point out approximate parallelogram hysteresis loops for gross sliding condition (Fig.7.a); elliptical shapes for the partial slip condition (Fig.7.b); a parallelogram with apparent gross sliding behaviour changing to an elliptical one for a mixed slip regime (Fig.7.c); an evolution of the loops shape for total slip during the test, Fig.7.a.

This analysis is repeated for the punch-plate configuration. A normal load per transverse width units of $P=2470 \mathrm{~N} / \mathrm{mm}$ and a displacement amplitude $\delta^{*}=50 \mu \mathrm{m}$ lead to a thin closed loop, characteristic of the partial slip regime, Fig.9.A.a., while, under the same normal load and displacement amplitude $\delta^{*}=150 \mu \mathrm{m}$, the loops present a large hysteresis describing the gross slip regime, Figure 9.A.b. Furthermore, like the cylinder-plate configuration and for the same reasons, there is an evolution of the loops for the total slip regime. The trend is qualitatively similar to the experimental study conducted in [33, 34].

\subsection{Wear profile}

The eroded profiles are presented for the same loading conditions, in column B of Fig.8 for the cylinder-plate case, and the column B of Fig.9 for punch-plate. Numerical wear simulations are in very good agreement with experimental observations, see, for exemple 


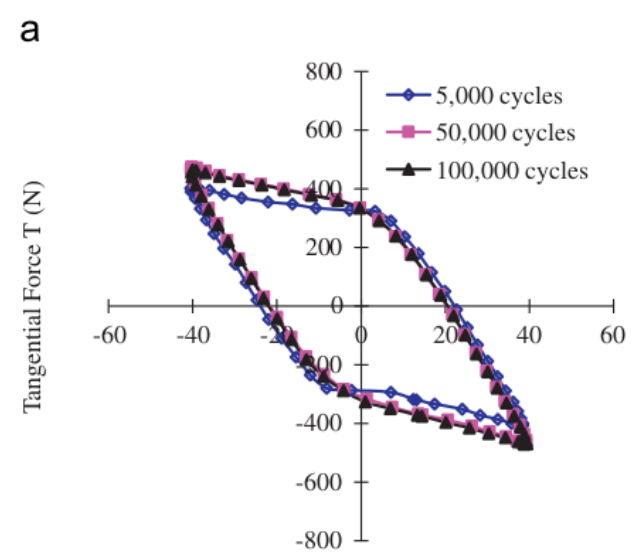

Displacement $\delta(\mu \mathrm{m})$

C b

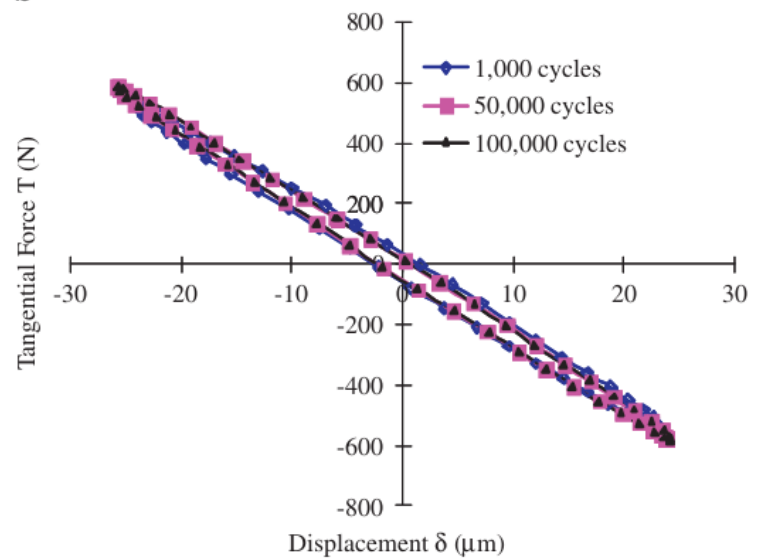

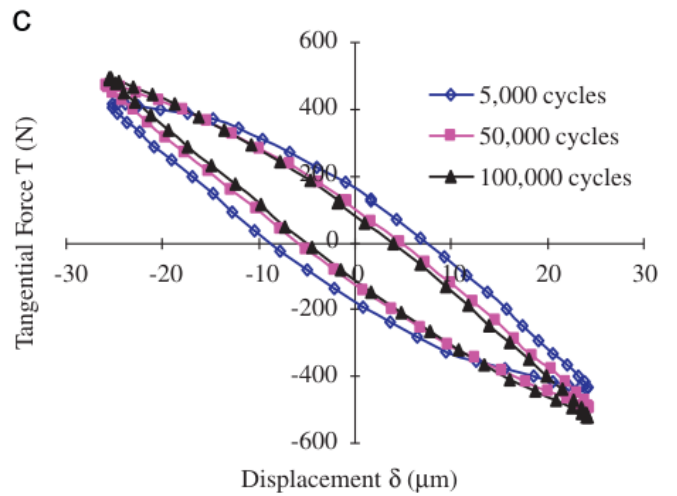

FiguRE 7: Measured tangential force versus displacement hysteresis loops for : (a) gross slip ; (b) partial slip ; and (c) mixed slip for a cylinder-on-plate configuration, [30].

$[27,16,32,33,34]$. Indeed, in the cylinder-plate case, wear is the predominant damage mode under gross slip regime, and the typical "U-shaped" wear scar is obtained. During the fretting test, surface erosion enlarges the contact area. For a loading condition in the mixed cracking/wear regime $\left(P=300 \mathrm{~N} / \mathrm{mm}, \delta^{*}=25 \mu \mathrm{m}\right)$, a maximum depth of around $80 \mu \mathrm{m}$ at the center of the wear scar is reached after 706608 cycles. For a loading condition $P=300 \mathrm{~N} / \mathrm{mm}$, $\delta^{*}=100 \mu \mathrm{m}$, the maximum depth is significantly larger than in the mixed cracking/wear zone, around $160 \mu \mathrm{m}$ at the center of the wear scar, in fewer cycles (314552 experimental cycles).

In contrast, Figures 8.B.a and b exhibited a "W-shaped" wear scar characteristic of the partial sliding conditions. For the loading conditions of partial slip, the wear is very low despite the large number of cycles. For $P=133 \mathrm{~N} / \mathrm{mm}$ and $\delta^{*}=5 \mu \mathrm{m}$, a maximum wear depth of about $0.7 \mu \mathrm{m}$ is obtained after 408828 cycles. Only one micrometer of maximum wear is observed after 1234856 cycles in the cracking zone $\left(P=300 \mathrm{~N} / \mathrm{mm}, \delta^{*}=10 \mu \mathrm{m}\right)$. There is no wear in partial slip. Qualitatively, the numerically computed wear profiles are in very good agreement with SEM, EDX and XPS surface analysis of plane fretting scars, presented in [32] and shown in Fig. 10, and also with numerical wear profiles from the 
(A)

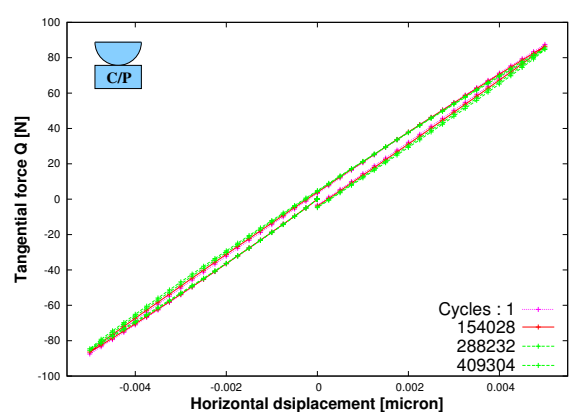

(a) No damage : $P=133 \mathrm{~N} / \mathrm{mm}, \delta^{*}=5 \mu \mathrm{m}$

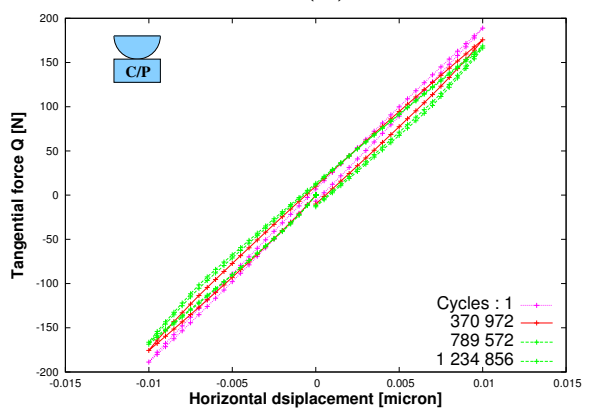

(b) Cracking : $P=300 \mathrm{~N} / \mathrm{mm}, \delta^{*}=10 \mu \mathrm{m}$
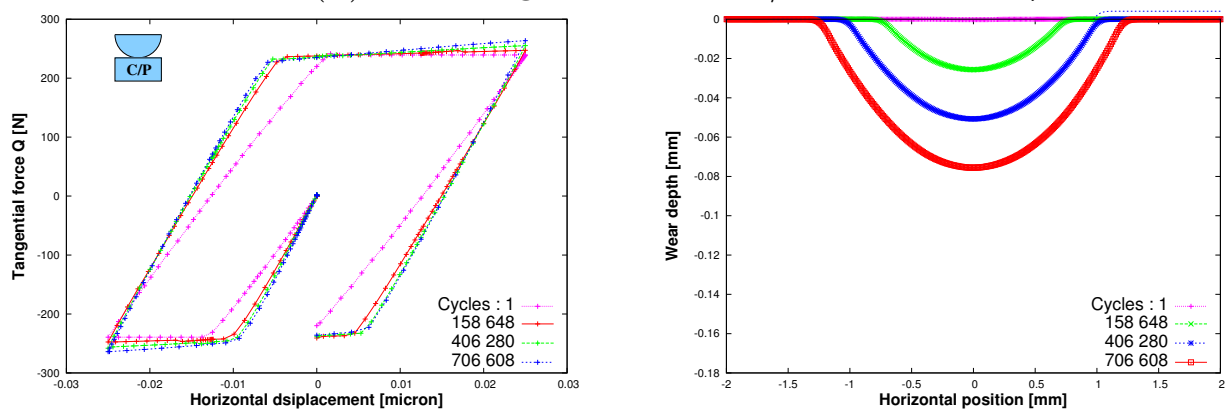

(c) Cracking/wear $P=300 \mathrm{~N} / \mathrm{mm}, \delta^{*}=25 \mu \mathrm{m}$
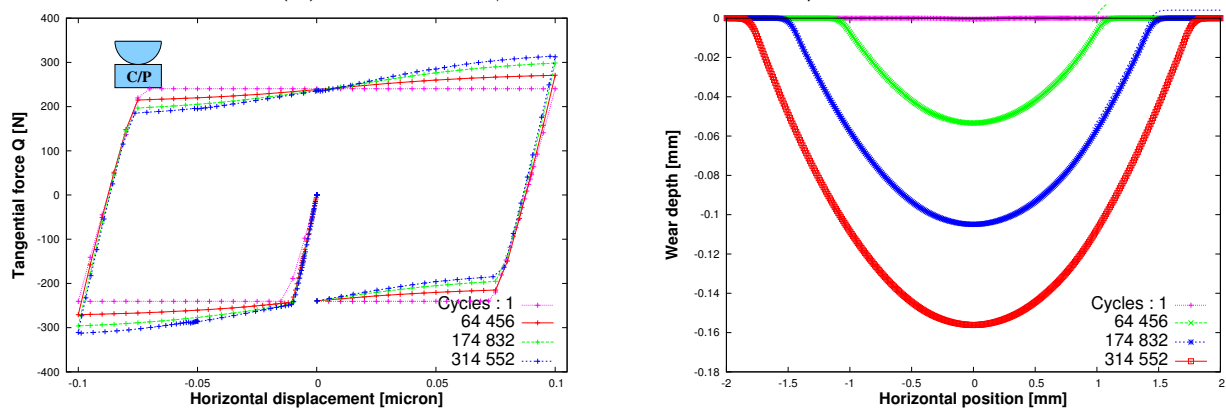

(d) Wear : $P=300 \mathrm{~N} / \mathrm{mm}, \delta^{*}=100 \mu \mathrm{m}$

FiguRE 8: (A) Numerical tangential force versus displacement hysteresis loops. (B) Wear profile of the plate for various loading cases : cylinder-plate configuration. 

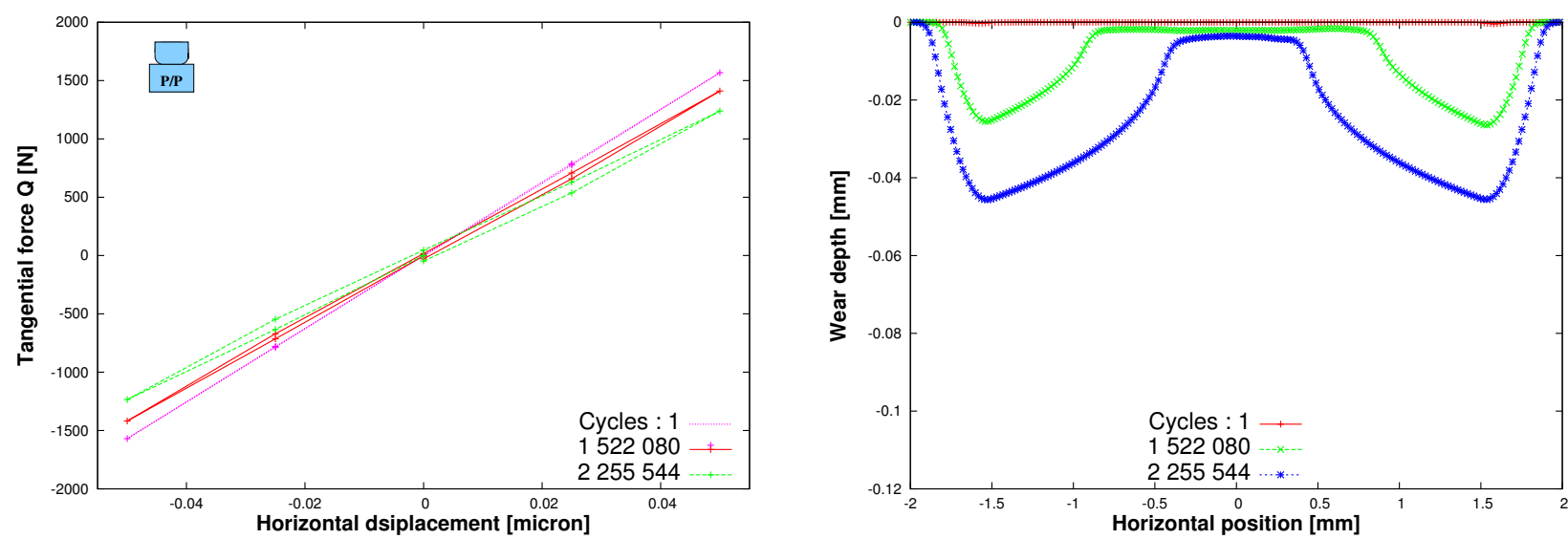

(a) Partial slip $P=2470 \mathrm{~N} / \mathrm{mm}, \delta^{*}=50 \mu \mathrm{m}$
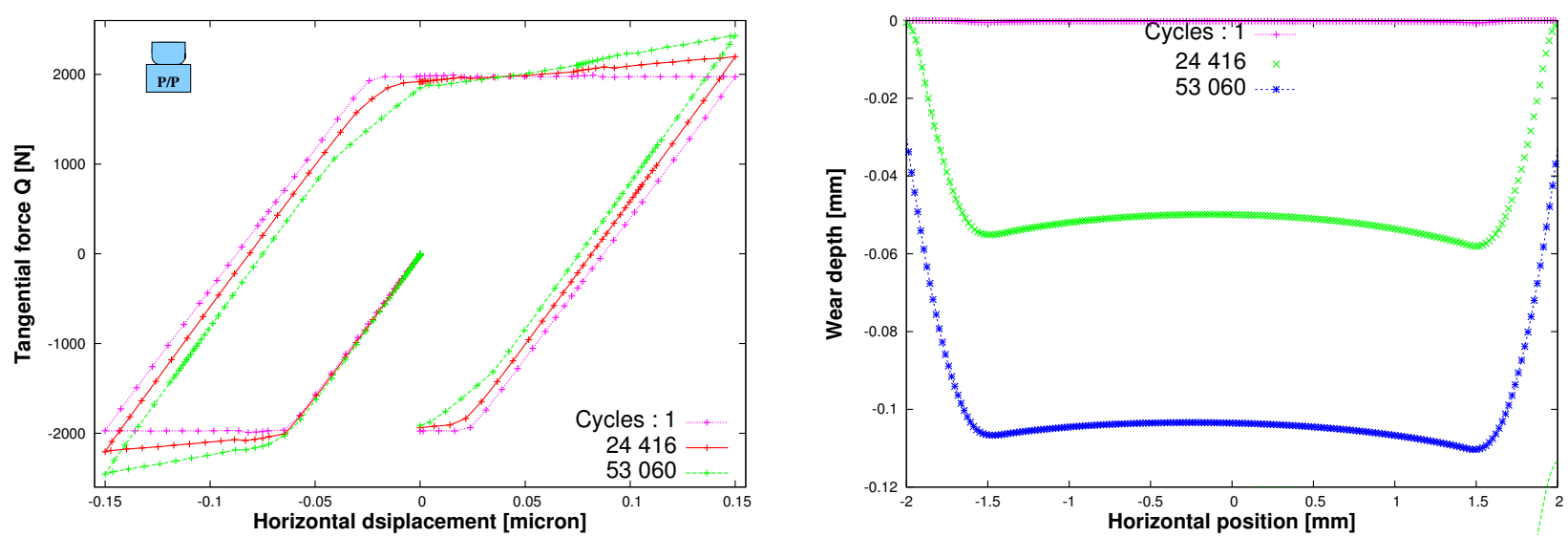

(b) Gross slip $P=2470 N / m m, \delta^{*}=150 \mu m$

Figure 9: (A) Numerical tangential force versus displacement hysteresis loops. (B) Wear profile of the plate for various loading cases : punch-plate configuration.

literature $[8,32,33,34,30]$. However, in experiments, the depth may be greater.

Next, the study is carried out for the punch-plate configuration. The wear profiles on the plate are represented in Fig.9.B. Under partial slip regime, Fig.9.B.a exhibits a "W-shaped" wear scar. After more than two million cycles, the maximum wear depth is around $50 \mu \mathrm{m}$. The wear extension under gross sliding regime is observed in Fig.9.B.b. The wear surface evolves, increases, converging to a flat distribution. After 50000 cycles, the wear depth extension is maximal at the lateral borders, around $100 \mu \mathrm{m}$. Qualitatively, the wear simulation leads to a typical profile consistent with the punch-on-plane experiments ( Fig.11, [12]) and with numerical simulations from literature [34]. In contrast to the cylinder-plane configuration, the lateral extension of the contact area is very small. The conclusions are similar to the previous configuration. There is almost no material removal under partial slip regime, while wear is the predominant damage mode under gross slip regime. 

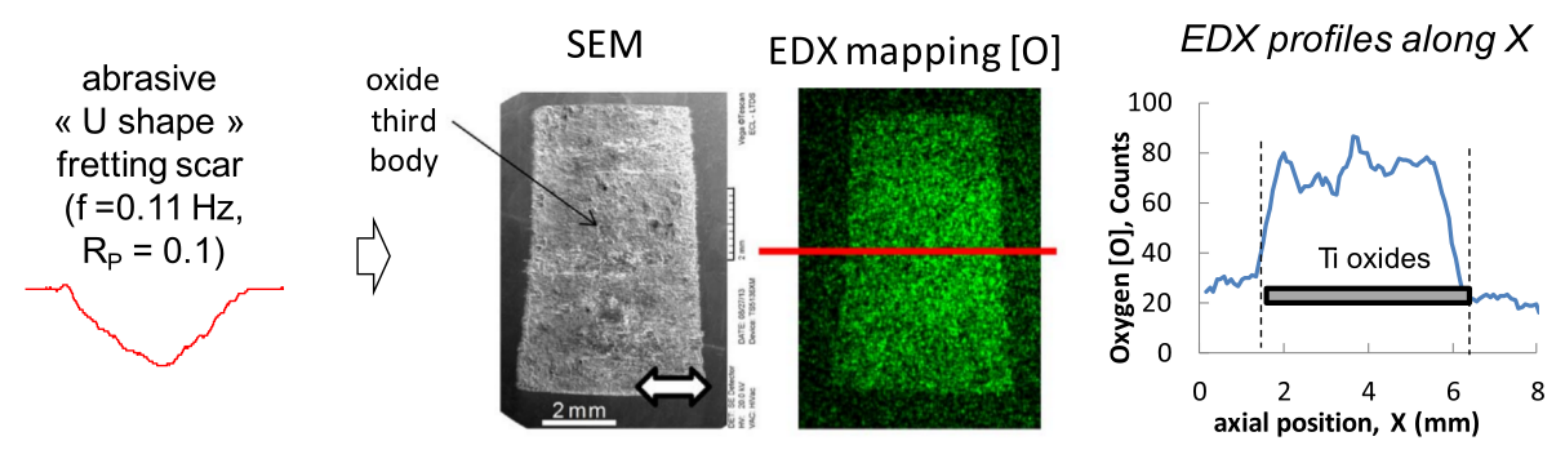

(a)

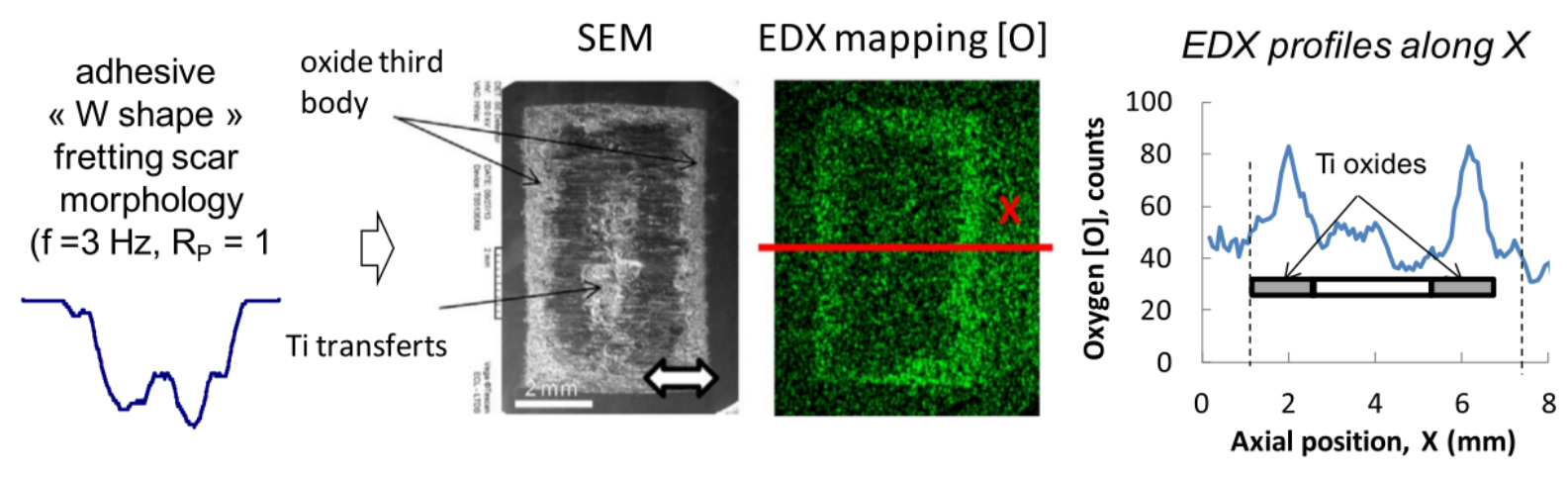

(b)

FIGURE 10: SEM and EDX surface analysis of plane scar morphology for the C/P configuration (a) U-shape under gross slip regime and (b) W-shape under partila slip regime, [32].

Briefly, all numerical wear shapes obtained are consistent with experimental observations (see, for example, [16, 32, 30, 34]), that is very encouraging for the wear simulation technique. For the case of partial slip, there is almost no wear and the profiles have a "W-shaped" scar, while, for gross slip, wear is the predominant degradation mode and a "U-shaped" wear scar is observed. The difference comes from the location of the wear zone, according to the contact geometries. For a cylinder-on-plate configuration, wear takes place in the middle of the print, meanwhile for a punch-on-plate configuration, the worn zones are at the edge of the contact. From numerical point of view, it is clear that the wear profiles are similar to those shown in $[6,8,16,12]$. However, the implementation of a non-local and stable wear criterion allows greater wear depths to be achieved (of the order of a few hundred microns against a few tens) while guaranteeing smooth worn profiles.

\subsection{Fatigue damage}

In this section, the SWT stress field and the resulting damage along the contact surface of the plate are analyzed at the beginning of the test and after a number of numerical fretting 

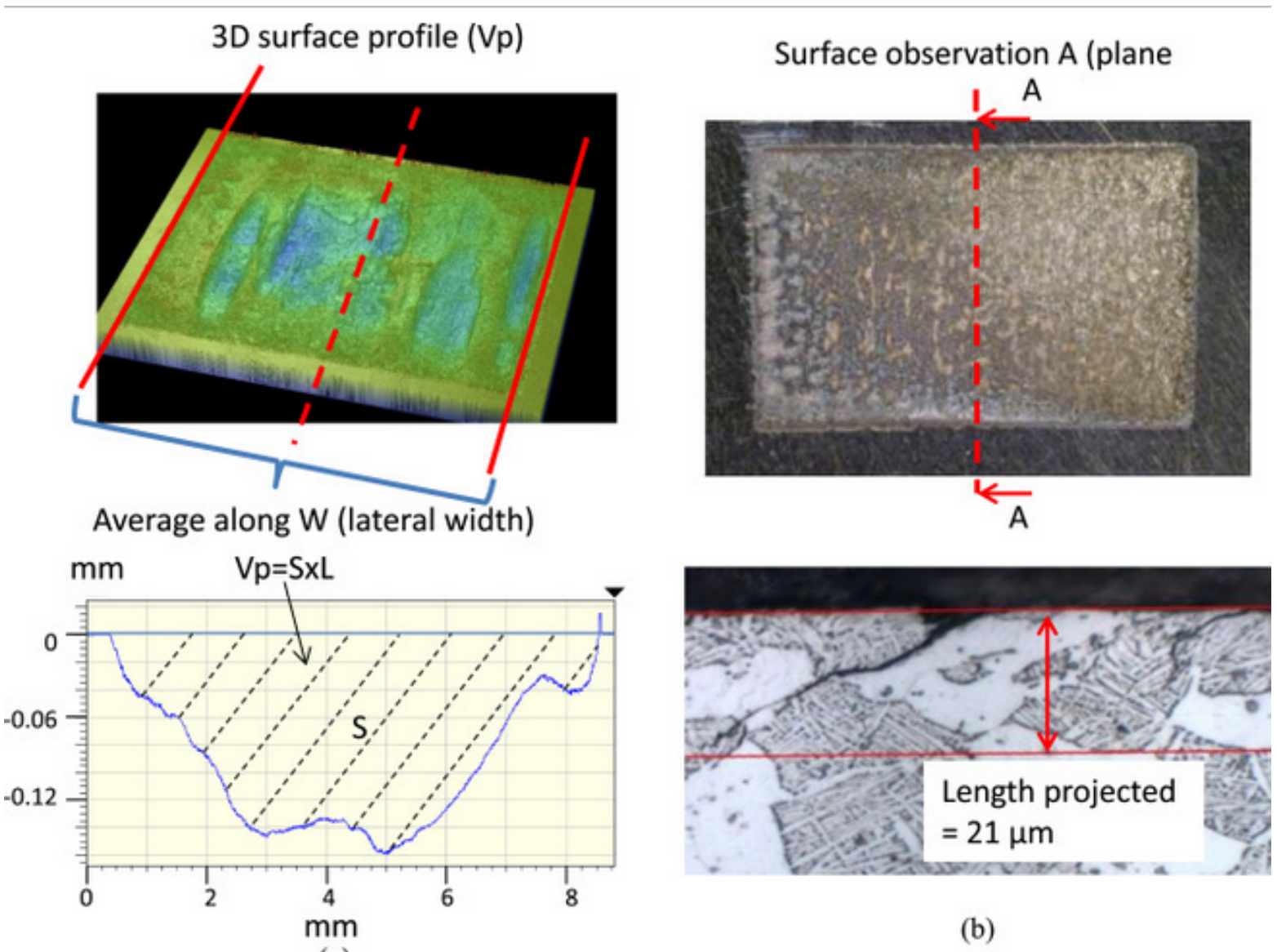

(a)

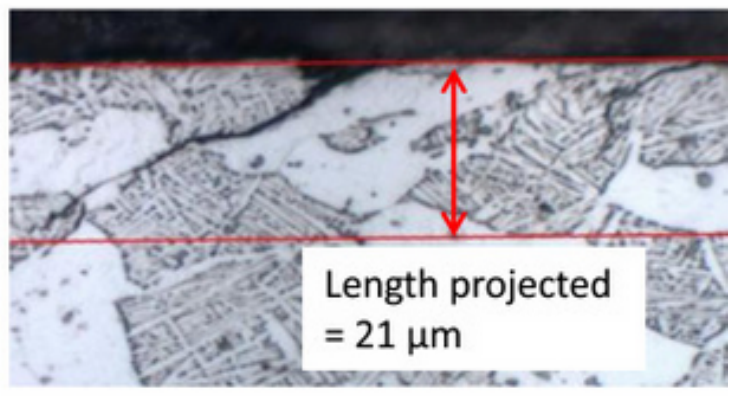

(b)

FIGURE 11: Fretting damage analysis (a) surface wear analysis determination of total wear volume (plane and pad fretting scars), gross slip (b) cracking analysis : localization and identification of maximum crack length, partial slip for the $\mathrm{P} / \mathrm{P}$ configuration, [12].

cycles, for the two geometries.

Figure 13 presents the case of the cylinder-plate fretting test. For a normal load per units width of $P=133 \mathrm{~N} / \mathrm{mm}$ and a displacement $\delta^{*}=5 \mu \mathrm{m}$, the equivalent SWT stress is smaller than the limit value, and decreases during the fretting test (Figure 13.A.a). Moreover, damage remains close to zero (Figure 13.B.a.) and there is almost no wear. This corresponds to a safe situation.

For $P=300 \mathrm{~N} / \mathrm{mm}$ and $\delta=10 \mu \mathrm{m}$, the equivalent SWT stress exceeds the limit value during the first cycles and increases during the fretting test, Fig.13.A.b. At the beginning, the location of the SWT stress peak value is at the contact edge, then moves inwards, towards the stick-slip boundary. The fatigue damage follows the same evolution. Moreover, no significant wear appears, see Section 6.2. Thereby, this case will generate a crack initiation. Under gross slip regime $(P=300 \mathrm{~N} / \mathrm{mm}, \delta=25 \mu \mathrm{m}$ and $P=300 \mathrm{~N} / \mathrm{mm}, \delta=100 \mu \mathrm{m})$, the equivalent SWT stress may exceed the limit value during the first cycles, then decreases significantly. Its 
distribution is affected by the erosion of the surface which affects shear and pressure profiles.

The location of the maximum equivalent stress is systematically observed at the surface near the contact edge. Its location however changes due to surface wear extension, Fig.13.A. The damage evolves in the same way for a small tangential displacement, Fig.13.B.c. Cracking is observed at the contact borders. In contrast, for a large tangential displacement, the maximum value increases, then progressively decreases during the fretting test and finally tends to zero. There is no possibility of crack initiation, because the damage zone is suppressed by the wear process.

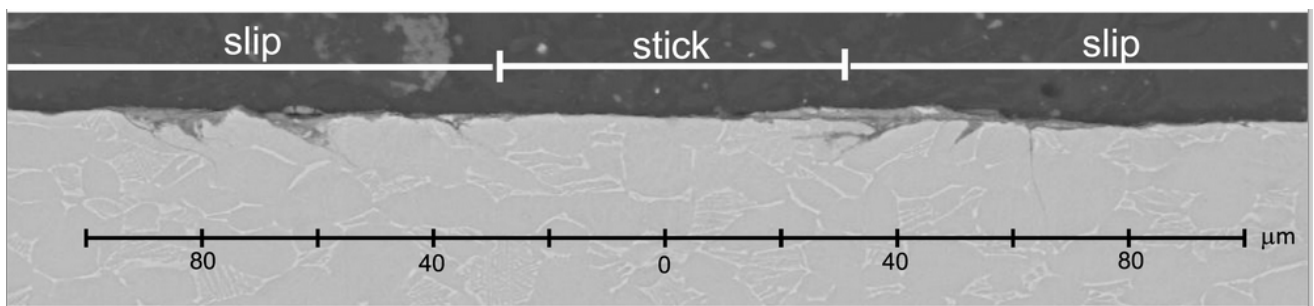

a)
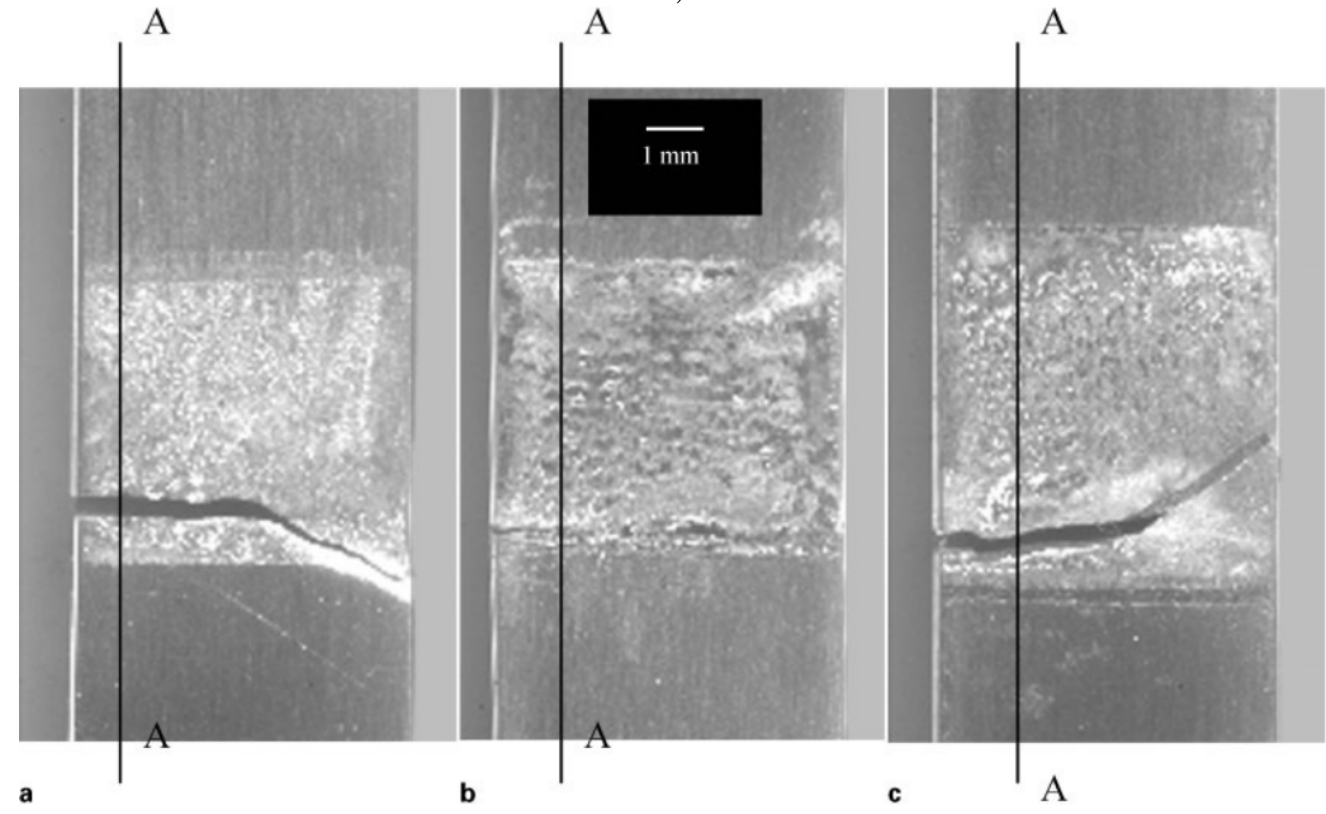

b)

Figure 12: a.)SEM image of flat specimen from partial slip. Crack initiation at the contact edge for a $\mathrm{C} / \mathrm{P}$ configuration, [35] ; b) Representative micrographs of fretting scar along with the crack initiation location for a $\mathrm{P} / \mathrm{P}$ configuration. Crack initiated near the trailing edge in all contact geometries [36].

In summary, the type of deterioration (erosion or crack initiation) is determined during the very first fretting cycles. If wear is at low level, fatigue damage is predominant and failure is predicted to occur at the contact edge. If the erosion goes faster, the areas experiencing damage deterioration are erased by the wear process. Thus, in the case of Fig.13.d, wear is predominant, meanwhile there is a competition between wear and damage in the case shown 
in Fig.13.c.

The strategy of the simulation of fatigue damage accumulation gives very satisfactory results. All numerical simulations match the experimental results described in Fridrici's fretting map [27]. Only partial slip conditions lead to fatigue damage. In addition, when there is a crack initiation prediction, the location is similar to what is experimentally observed, $\mathrm{i}$. e. at the edge of the contact zone, Fig.12 of [35].

The trends are similar for the punch-plate fretting test, Fig.14. Under partial slip, the maximum equivalent SWT exceeds the limit value, and increases during the fretting test. Fatigue damage increases, and there is almost no wear. The position of the maximum values moves inwards, and reaches the stick-slip boundary, Fig.14.a. Consequently, the fretting test will end with crack nucleation. Under gross slip, like for the cylinder/plane configuration, the equivalent SWT stress remains maximum at the contact edge and exceeds the limit value. However, the maximum value is concentrated at the same position, since there is no contact area extension. Moreover, fatigue damage increases and exceeds the critical value, Fig.14.B.a and 14.B.b. Then, for a punch-plate configuration, the maximum risk is predicted at the contact borders independently of sliding conditions. These conclusions are in good agreement with the fretting scar examination of [12,35] (Fig.11.b and 12.b.) showing crack occurrence at the contact edge for both partial and gross slip conditions.

The confrontation of the wear (Section 6.2) and fatigue (Section 6.3) confirms the previous conclusions, and highlights the excellent agreement of the numerical simulations with the experimental data taken from the literature $[12,35]$. This new strategy makes it possible to better locate sites for crack initiation compared to previous numerical studies $[27,16,12,10$, $19,37]$.

\subsection{Influence of surface wear on fretting damage distribution}

This section clarifies the effect of wear on the risk of crack initiation. The evolution of the fatigue damage during the wear process is illustrated in Fig.15 and Fig.16 at the beginning of the test and after a number of successive profiles for the two contact geometries. Whatever the contact geometry, the conclusions are similar. Under partial slip, fatigue damage increases, since there is almost no wear (Fig.15.a and Fig.16.a). This confirms the risk of crack initiation. For the gross slip regime, wear transforms the plate surface during the cycles, and the areas affected by fatigue damage are eliminated. That is how the wear process tends to suppress crack initiation (Fig.15.b and Fig.16.b). 
(A)

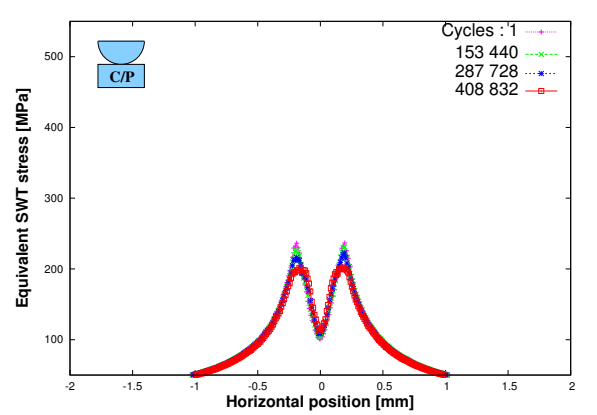

(a) No damage : $P=133 \mathrm{~N} / \mathrm{mm}, \delta^{*}=5 \mu \mathrm{m}$

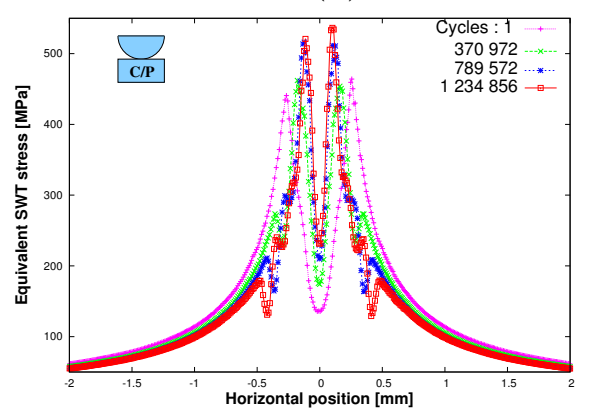

(b) Cracking : $P=300 \mathrm{~N} / \mathrm{mm}, \delta^{*}=10 \mu \mathrm{m}$

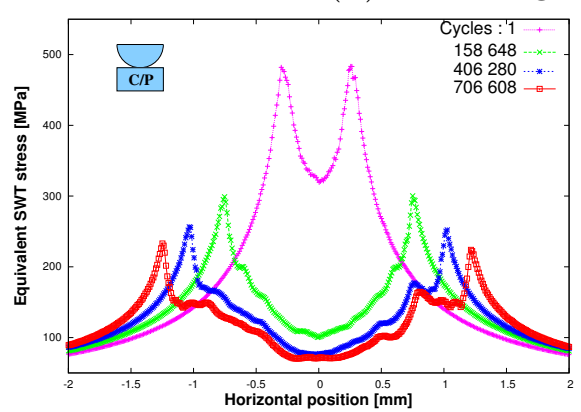

(c) Cracking/wear $P=300 \mathrm{~N} / \mathrm{mm}, \delta^{*}=25 \mu \mathrm{m}$
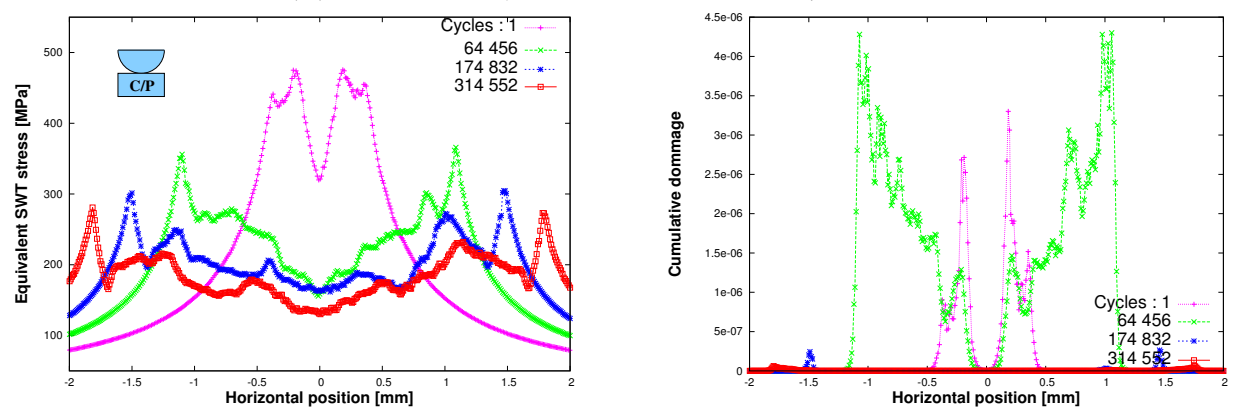

(d) Wear : $P=300 \mathrm{~N} / \mathrm{mm}, \delta^{*}=100 \mu \mathrm{m}$

Figure 13: Plots obtained for profiles 1, 250, 500, 750 for various loading conditions for the cylinder-plate case (A) SWT stress, (B) Damage. 

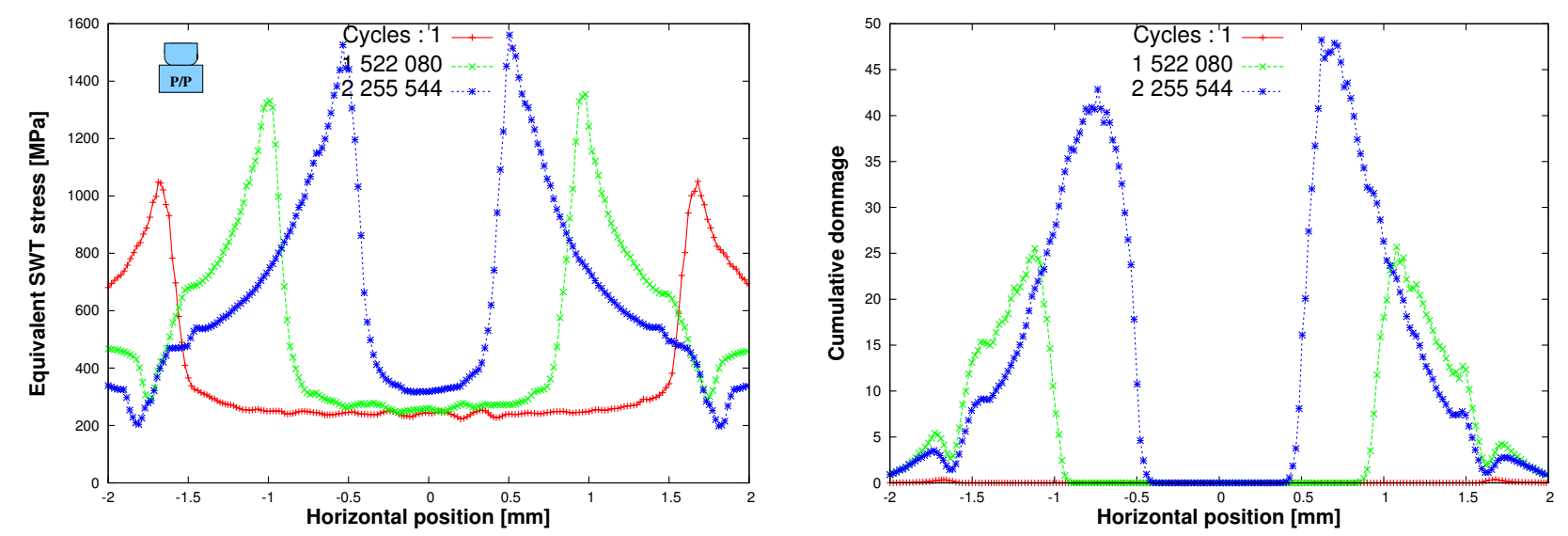

(a) Partial slip $P=2470 \mathrm{~N} / \mathrm{mm}, \delta^{*}=50 \mu \mathrm{m}$
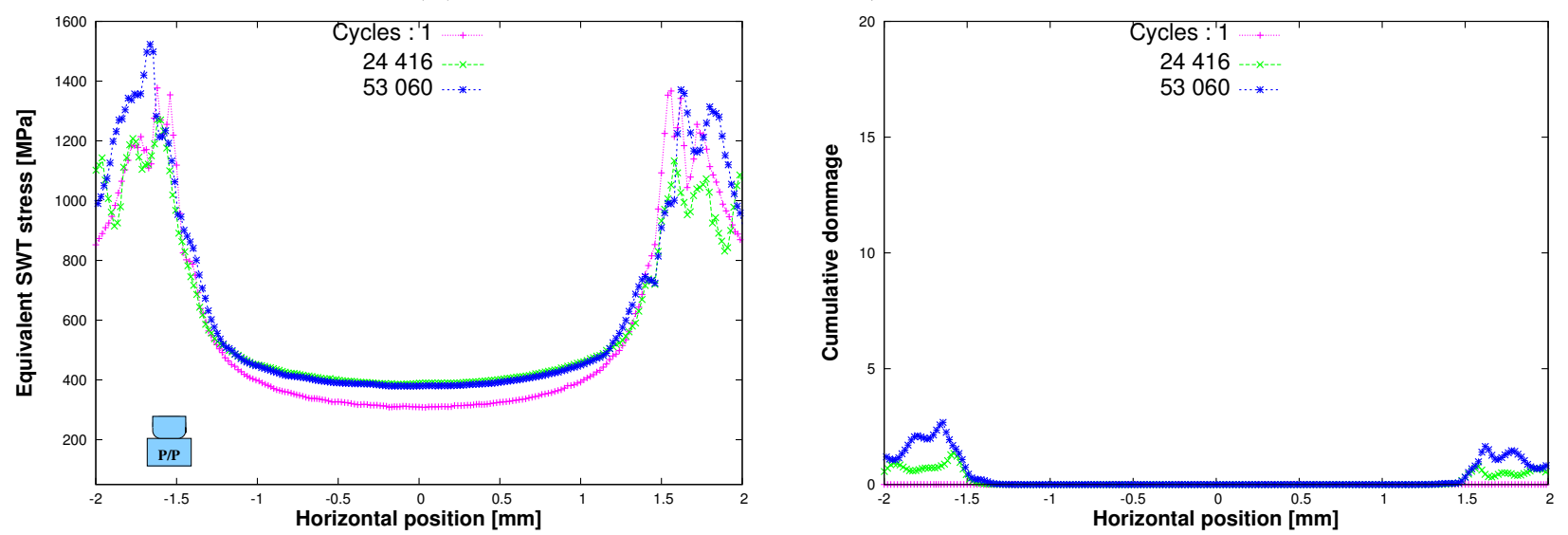

(b) Gross slip $P=2470 \mathrm{~N} / \mathrm{mm}, \delta^{*}=150 \mu \mathrm{m}$

FigURE 14: Plots obtained for profiles 1, 250, 500, 750 for various loading conditions for the punch-plate case (A) SWT stress, (B) Damage.

\section{Conclusions}

The present paper suggests a consistent and robust finite-element computational framework devoted to the simulation of fatigue damage evolution in presence of a wear process in fretting contact. A special attention is paid to the effect of the progressive erosion on crack nucleation. The local wear depth depends on the average friction energy for a given profile. The non-local quantity characterising accumulated frictional dissipation determines the local wear depth, which is taken into account by a remeshing procedure. Simultaneously, a Smith-Watson-Topper model is used to calculate fatigue damage, which is accumulated by means of a linear Miner's rule.

A numerical investigation is performed for two Ti6Al4V on Ti6Al4V contact geometries : cylinder-on-plate and punch-on-plane, under partial and gross slip conditions. The numerical 

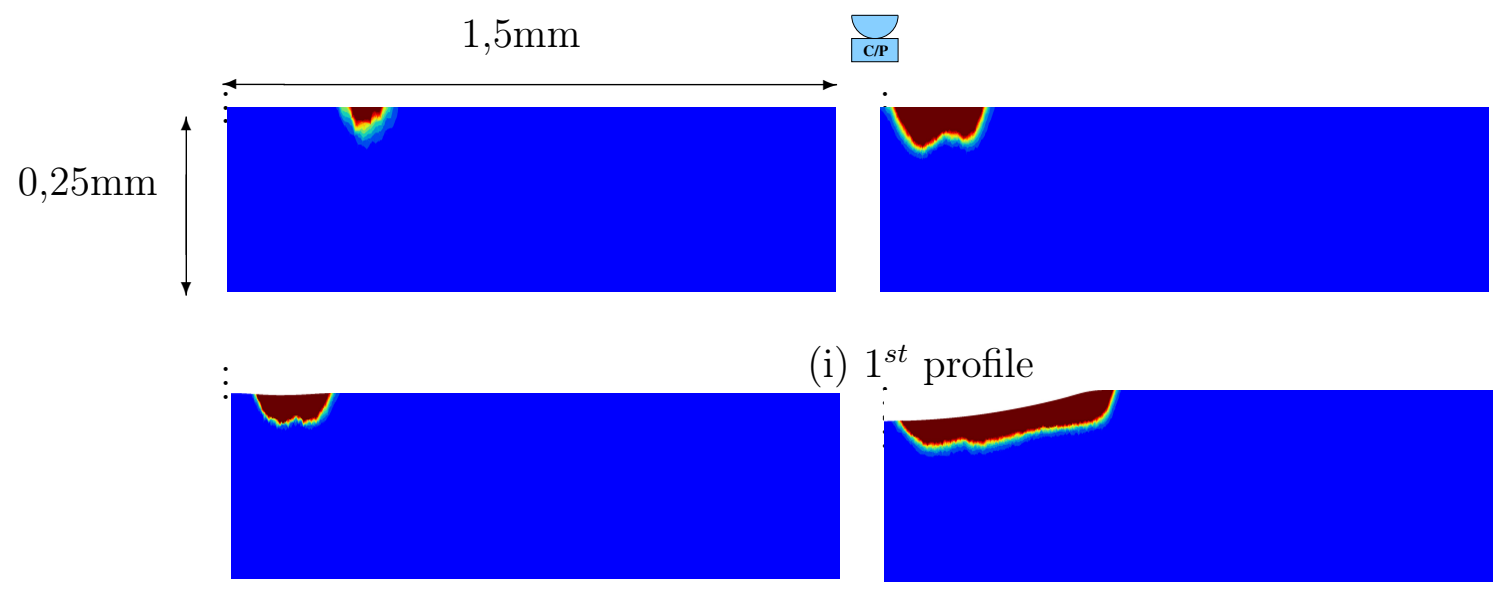

(ii) $250^{\text {th }}$ profile

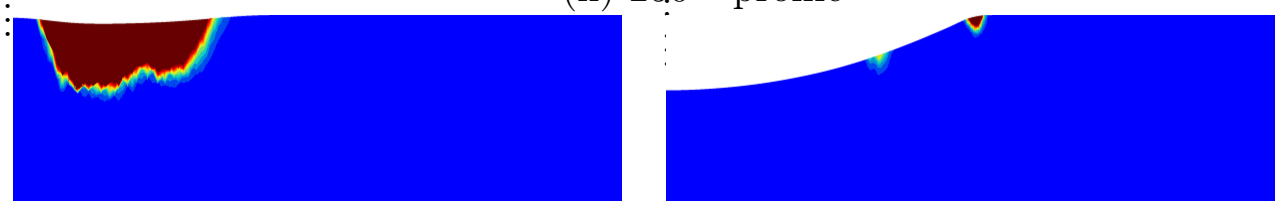

(iii) $500^{\text {th }}$ profile

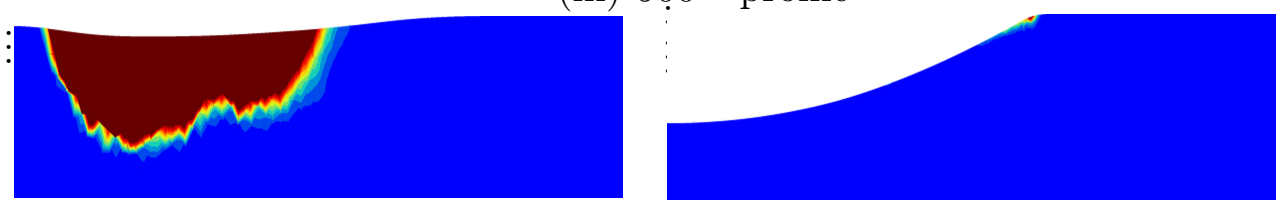

(iv) $750^{\text {th }}$ profile

(a) Partial slip : $P=300 \mathrm{~N} / \mathrm{mm}, \quad$ (b) Gross slip : $P=300 \mathrm{~N} / \mathrm{mm}$,

$$
\delta^{*}=10 \mu m
$$

$$
\delta^{*}=100 \mu m
$$

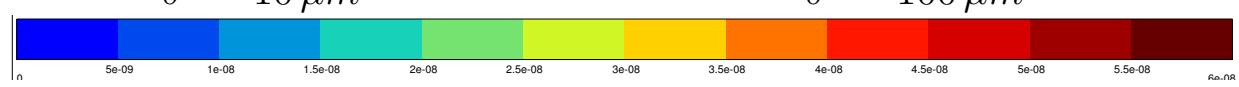

FiguRE 15: Fatigue damage contour on the plate for the cylinder/plate case represented on the right half mesh : dynamized figures.

simulations are in a very good agreement with experimental data taken from the literature,which is a very encouraging result proving the accuracy of the damage and wear models and also the adequacy of their interplay simulated in the finite element framework. Under partial slip, there is almost no material removal, so the fatigue damage increases, and the risk of crack nucleation dominates. Under gross slip, wear transforms the surface, the areas affected by fatigue damage are eliminated, which tends to suppress crack initiation.

Although several aspects, such as variation of the friction coefficient, possible surface coating, micro-structural aspects, presence of the third body, oxidation effects, etc, are omitted in this numerical model, the numerical results are very encouraging since they are close to the experimental results. One of the main limitations of the present study is that it was limited 


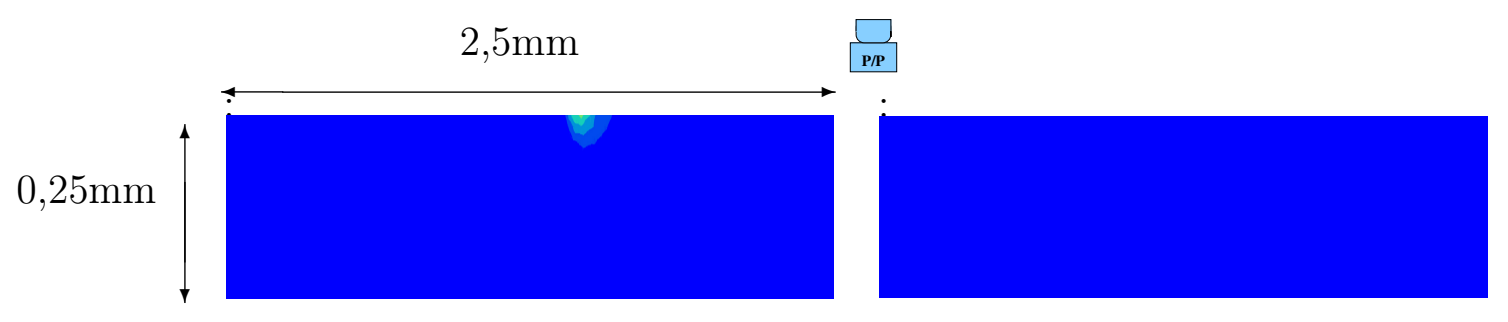

(i) $1^{r d}$. profile

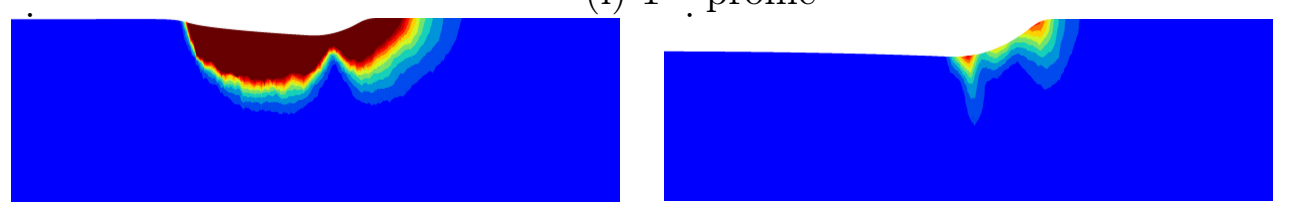

(ii) $250^{\text {th }}$ profile

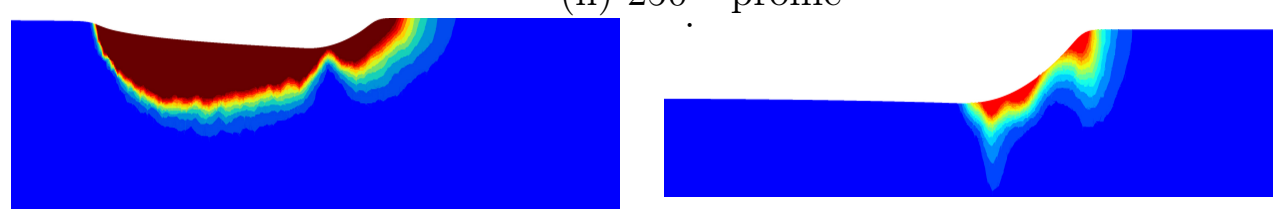

(iii) $500^{\text {th }}$ profile
(a) Partial slip : $P=2470 \mathrm{~N} / \mathrm{mm}$, $\delta^{*}=50 \mu \mathrm{m}$
(b) Gross slip : $P=2470 \mathrm{~N} / \mathrm{mm}$, $\delta^{*}=150 \mu m$

FIGURE 16: Fatigue damage contour on the plate for the punch/plate case represented on the right half mesh : dynamized figures.

to two-dimensional case. An extension to three-dimensional framework is in progress.

\section{Acknowledgements}

The work presented in this paper was supported by Safran Aircraft Engine.

\section{Références}

[1] Waterhouse R.-B. Fretting Fatigue. Applied Science., 1981.

[2] Vingsbo O. and Soderberg S. On fretting maps 1. Wear, 126(2) :131-147, Sep 1988.

[3] Vincent L., Berthier Y., and Godet M. Testing methods in fretting fatigue : a critical appraisal. In ASTM STP 1159 on standardization of fretting fatigue test methods and equipment, West Conshocken,PA. ASTM,pages 33-48, 1992.

[4] Archard J.-F. Contact and rubbing of flat surfaces. Journal of Applied Physics, 24 :981988, 1953. 
[5] Fouvry S., Vincent L., and Kapsa P. Quantification of fretting damage. Wear, 200(12) :186-205, Dec 1996.

[6] Johanson L. Numerical simulation of contact pressure evolution in fretting. Journal of Tribology, $116: 247-254,1994$.

[7] Cruzado A, Urchegui M.A, and Gomez X. Finite element modeling of fretting wear scars in the thin steel wires : Application in crossed cylinder arrangements. Wear, $318: 98-105$, 2014.

[8] Basseville S. and Cailletaud G. An evaluation of the competition between wear and crack initiation in fretting conditions for Ti-6Al-4V alloy. Wear,, (328-329) :443-455, 2015.

[9] Szolwinski M.-P and Farris T.-N. Mechanics of fretting fatigue crack formation. Wear, 198(1-2) :93-107, Oct 1996.

[10] Garcin S., Fouvry S., and Heredia S. A FEM fretting map modeling : Effect of surface wear on crack nucleation. Wear, pages 145-159, 2015.

[11] Madge J-J, Leen S-B, and Shipway P-H. The critical role of fretting wear in the analysis of fretting fatigue. Wear, 263(Issues 1-6) :542-551, 2007.

[12] P. Arnaud, S. Fouvry, and S. Garcin. Wear rate impact on Ti-6Al-4V fretting crack risk : Experimental and numerical comparaison between cylinder/plane and punch/plane contact geometries. Tribology International, $108: 32-47,2017$.

[13] Cruzado A, Leen S.B, Urchegui M.A, and Gomez X. Finite element simulation of fretting wear and fatigue in the thin steel wires. International Journal of Fatigue, $55: 7-21,2013$.

[14] Araujo J-A and Nowell D. The effect of rapidly varying contact stress fields on fretting fatigue. Int J Fatigue, 24 :763-775, 2002.

[15] Fouvry S., Kapsa Ph., and Vincent L. A multiaxial fatigue analysis of fretting contact taking into account the size effect. ASTM STP, 1367 :167-182, 2006.

[16] McColl I.-R., Ding J., and Leen S.-B. Finite element simulation and experimental validation of fretting wear. Wear, 256(11-12) :1114-1127, 2004.

[17] Paulin C., Fouvry S., and Meunier C. Finite element modelling of fretting wear surface evolution : Application to a Ti-6Al-4V contact. Wear, 264 :26-36, 2008.

[18] Gallego L, Fulleringer B, Deyber S, and Nélias D. Multiscale computation of fretting wear at the blade/disk interface. Tribology International, 43 :708-718, 2010.

[19] Madge J-J, Leen S-B, and Shipway P-H. A combined wear and crack nucleation-propagation methodology for fretting fatigue prediction. Int J Fatigue, $30: 1509$ 1528, 2008. 
[20] http ://www.zset-software.com/ version Z8.6.7 (2017).

[21] Francavilla A. and Zienkiewicz O.-C. A note on numerical computation of elastic contact problems. Int. J. Numer. Meth. Engng, 9 :913-924, 1975.

[22] Jean M. Frictional contact in collections of rigid or deformable bodies : numerical simulation of geomaterial motions. Studies in Applied Mechanics, 42 :463-486, 1995.

[23] Yastrebov V.A. Numerical Methods in Contact Mechanics. ISTE-WILEY, 2 edition, 2013.

[24] Geuzaine C. and Remacle J.-F. Gmsh : a three-dimensional finite element mesh generator with built-in pre- and post-processing facilities. International Journal for Numerical Methods in Engineering, 79(11) :1309-1331, 2009.

[25] Mary C and Fouvry S. Numerical prediction of fretting contact durability using energy wear approach : optimisation of finite-element model. Wear, 263 :440-450, 2007.

[26] Smith K.-N., Watson P., and Topper T.-H. A stress-strain function for the fatigue of metals. Journal of Materials, 5(4) :767-778, Dec 1970.

[27] Fridrici V. Fretting d'un alliage de titane revêtu et lubrifié application au contact aube/disque. PhD thesis, École Centrale de Lyon, Ecully, 2002.

[28] Jin O and Mall S. Effects of slip on fretting behaviour : experiments and analyses. Wear, $256: 671-684,2004$.

[29] Sabelkin V and Mall S. Relative slip on contact surface under partial slip fretting fatigue condition. Strain, 42(1) :11-20, 2006.

[30] Ding J, Bandak G, Leen S-B., Williams E-J, and Shipway P-H. Experimental characterisation and numerical simulation of contact evolution effect on fretting crack nucleation for Ti-6Al-4V. Tribology International, 42 :1651-1662, 2009.

[31] Mohd Tobi A.-L., Shipway P.-H., and Leen S.-B. Gross slip fretting wear performance of a layered thin w-dlc coating : damage mechanisms and life modelling. Wear, 271 :1572$-1584,2011$.

[32] Fouvry S., Arnaud P., Mignot A., and Neubauer P. Contact size, frequency and cyclic normal force effects on Ti-6Al-4V fretting wear processes : An approach combining frcition power and contact oxygenation. Tribology International,, (111) :460-473, 2017.

[33] Mary C, Fouvry S, Martin J-M, and Bonnet B. High temperature fretting wear of a Ti alloy/CuNiIn contact. Surface \& Coating technlogy, 203 :691-698, 2008.

[34] Mary C, Fouvry S, Martin J-M, and Bonnet B. Pressure and temperature effects on fretting wear damage of a CuNiIn plasma coating versus Ti17 titanium alloy contact. Wear, $272: 18-37,2011$. 
[35] Mohd Tobi A.-L., Ding J., Bandak G., Leen S.-B., and Shipway P.-H. A study on the interaction between fretting wear and cyclic plasticity for ti-6al-4v. Wear, $267: 270-282$, 2009.

[36] Mall S, Naboulsi S, and Namjoshi S.A. Contact geometry effects on fretting fatigue crack initiation behaviour of ti-6al-4v. Tribology - Materials, Surfaces \& Interfaces, $2: 1: 25-32,2008$.

[37] Shen F, Hu W, Voyiadjis G, and Meng Q. Effet of fatigue damage and wear on fretting fatigue under partial slip condition. Wear, pages 394-405, 2015. 


\section{A. Optimization of the parameters of the wear equation}

Wear process involves three parameters $\left(\rho, R, \Delta h_{0}\right)$ which must be optimized to avoid altering the wear simulations, equation 2 . For each simulation, a similar study to the one presented below was conducted and a set of parameters was determined.

The parameter analysis is presented only for the cylinder-plate configuration under gross slip condition $\left(\mathrm{P}=300 \mathrm{~N} / \mathrm{mm}, \delta^{*}=100 \mu \mathrm{m}\right)$. To determine the values of the three appropriate parameters, the profiles of wear and friction density energy were analyzed after several successive profiles $N_{p}$, Fig.17.A and B.

Firstly, the analysis is focused on the parameter $\rho$. Four values $(20,40,80$ and $100 \mu m)$ were choosen. To properly analyze the parameter $\rho$, the other two parameters $R$ and $\Delta h_{0}$ must not influence the results. Thus, it is therefore necessary to choose a large cut-off distance $R$, and a low accelerator factor $\Delta h_{0}$. The parameters $R$ and $\Delta h_{0}$ were fixed respectively to $1000 \mu \mathrm{m}$ and $0.2 \mu \mathrm{m}$. A low value of the parameter $\rho$ leads to instabilities of the energy (Fig.17.B.a.) and the numerically computed wear lower than expected, (Fig.17.A.a.). Beyond a value of 40 micrometers, the profiles are stable and the numerically calculated wear depth is in agreement with the expected wear, $p \times \Delta h_{0}$. However, this parameter must remain low otherwise the contact width will be overestimated. Thus, the choosen parameter $\rho$ was $40 \mu \mathrm{m}$.

The next step focuses on the cut-off distance $R$. Four values were taken $(40,100,500$, $1000 \mu \mathrm{m}$ ). The parameters $\rho$ is now equal to $40 \mu \mathrm{m}$ and the imposed wear depth $\Delta h_{0}$ must be low, equal to $0.2 \mu \mathrm{m}$. A too small parameter $R$ underestimates the erosion and leads to instabilities, Fig.17.b. Beyond a critical value, the evolution of wear profiles and of energy is stable and similar. The calculated erosion is in agreement with the imposed wear $p \times \Delta h_{0}$ and the contact width remains unchanged. Consequently, the value $R=100 \mu m$ is chosen.

The last step consists in determining the optimal accelerator factor $\Delta h_{0}$. Three accelerator factor were tested : 20,2 and $0.2 \mu \mathrm{m}$. The parameter $\rho$ is $40 \mu \mathrm{m}$ and the cut-off distance $R$ is $100 \mu \mathrm{m}$. The results show that the acceleration factor should not be too high, otherwise the energy and wear profiles are totally insubstantial, Fig.17.c. Higher values lead to instabilities and the erosion is underestimated. Thus, the accelerator factor $\Delta h_{0}$ must remain $0.2 \mu \mathrm{m}$.

In the case of the cylinder-plate configuration, under gross slip condition ( $\mathrm{P}=300 \mathrm{~N} / \mathrm{mm}$, $\left.\delta^{*}=100 \mu \mathrm{m}\right)$, the set of parameter selected is $\left(\rho, R, \Delta h_{0}\right)=(40 \mu \mathrm{m}, 100 \mu \mathrm{m}, 0.2 \mu \mathrm{m})$. 

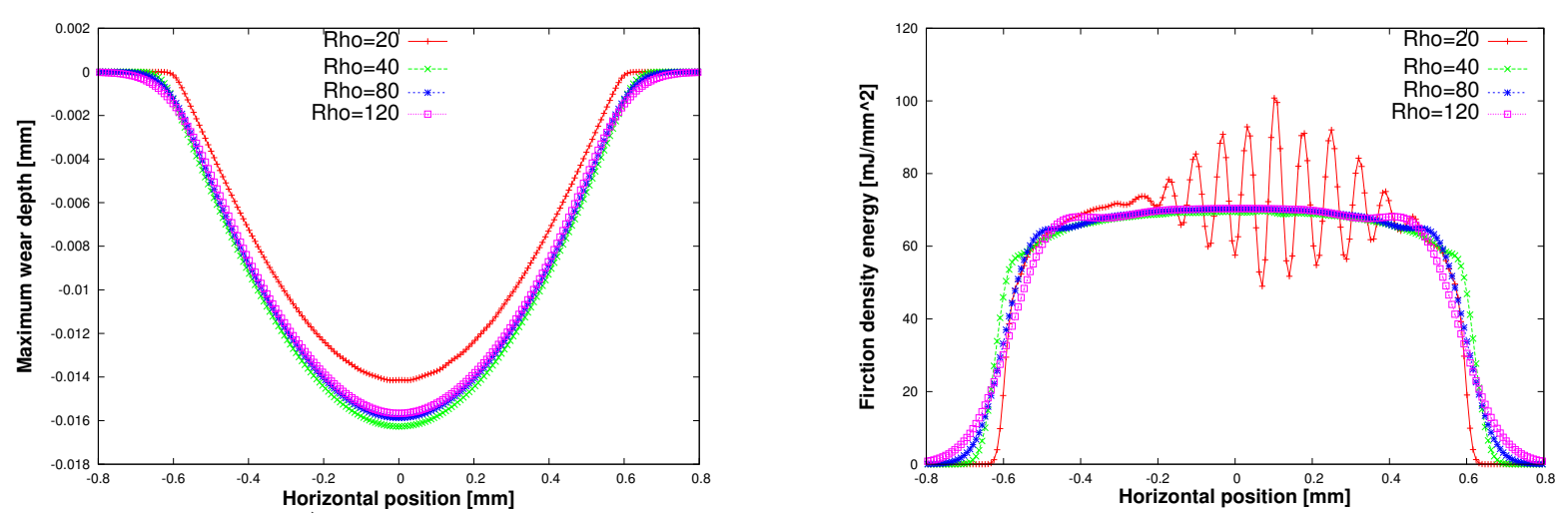

a). Influence of the parameter $\rho$. $R=1000 \mu m, \Delta h_{0}=0.2 \mu m$
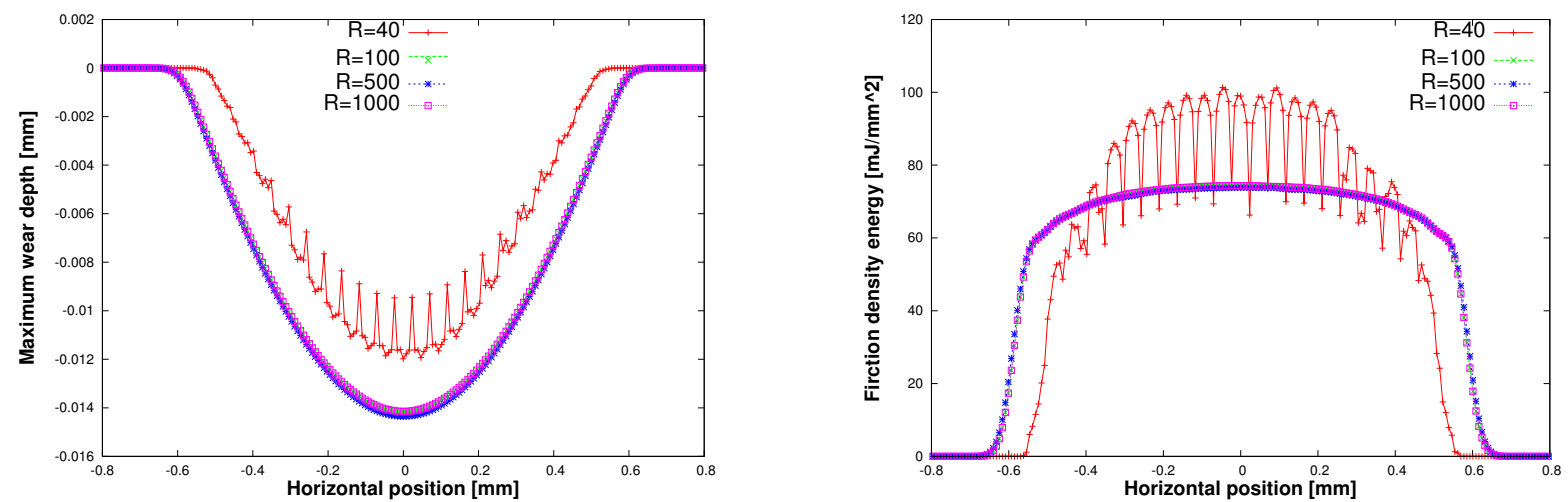

b). Influence of the parameter $R . \rho=40 \mu m, \Delta h_{0}=0.2 \mu m$
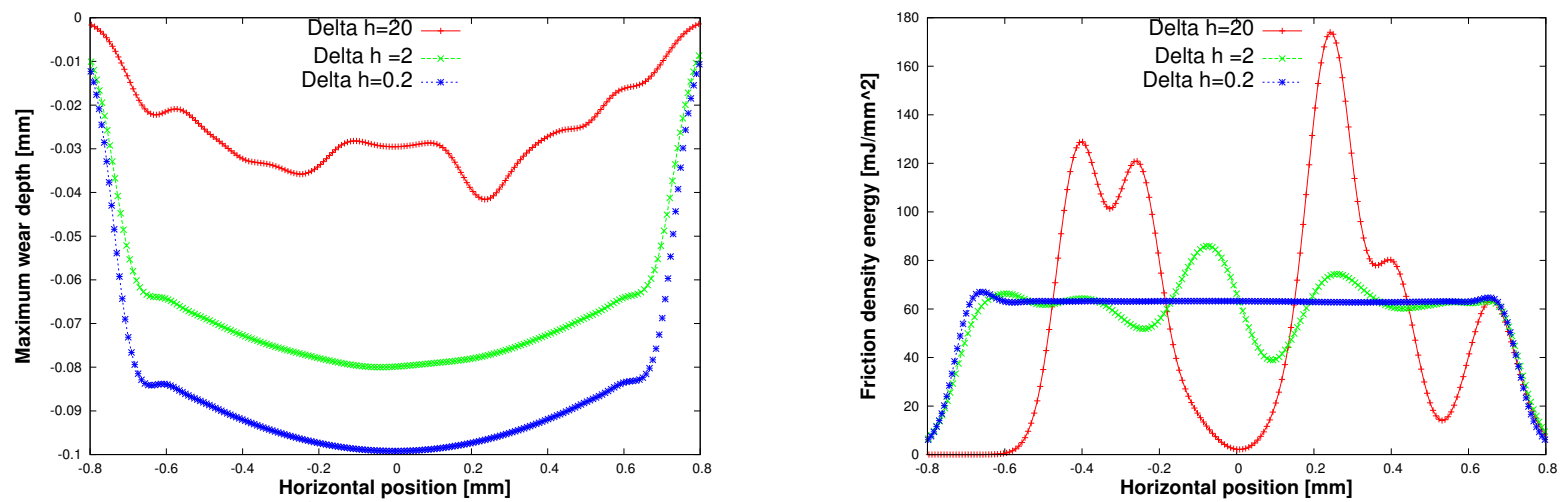

c). Influence of the parameter $\Delta h_{0} . \rho=40 \mu m, R=1000 \mu m$

Figure 17: Plots obtained after $p$ successive profiles for the cylinder-plate case for the loading conditions $P=300 \mathrm{~N} / \mathrm{mm}, \delta=100 \mu \mathrm{m}$ (A) Wear profile, (B) Friction density energy . 


\section{B. Existence of an Apparent Coefficient of friction (ACof)}

The purpose of this appendix is to explain the evolution of the fretting loops during the fretting cycles. This evolution results from the wear process that generates an increase of an Apparent Coefficient of friction (ACof) which is presented here.

In Fig.18, the slope of the segments $(A, B)$ and $(C, D)$ is constant during the fretting test. There is no slip during these periods. In contrast, the line $(B, C)$ corresponds to the slip period. The slope increases during the fretting cycles. This slope variation corresponds to the

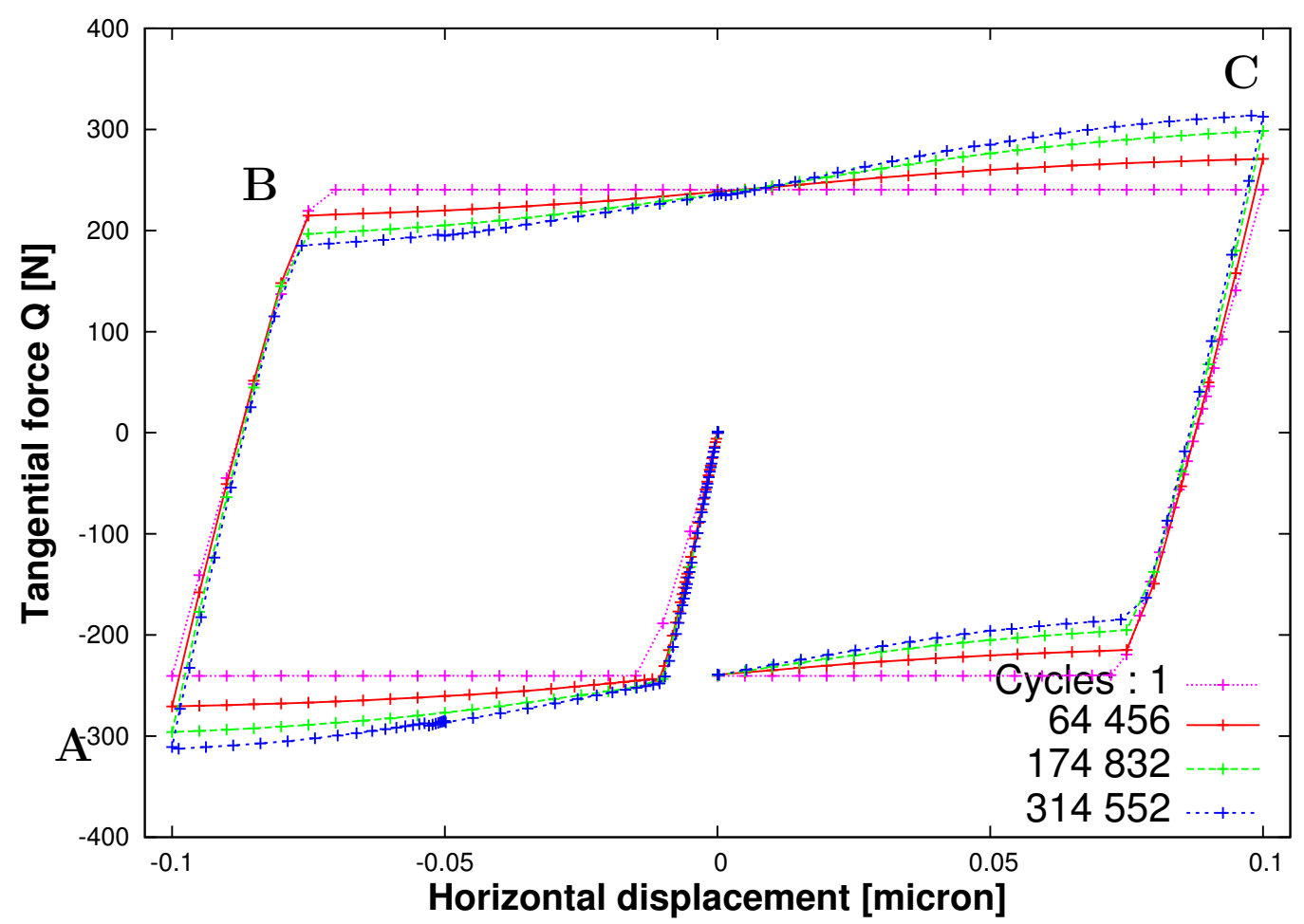

Figure 18: Numerical tangential force versus displacement hysteresis loops during the fretting test, $P=$ $300 \mathrm{~N} / \mathrm{mm}, \delta=100 \mu \mathrm{m}$.

existence of an apparent coefficient of friction (ACof) which depends on the wear profile and the sliding direction.

For the first cycle, the contact surfaces are tangent. The normal load $P$ is perpendicular to the plane, the tangential load $Q_{1}$ is parallel to the plane, Fig.19.a. The Cof $\mu$ is constant and is expressed by

$$
\mu=\frac{Q_{1}}{P}
$$

After $p$ fretting cycles, the plate surface is worn and the contact takes place on an inclined surface, Fig.19.b. The Cof is then given by

$$
\mu=\frac{Q_{1} \cos (\alpha)-P \sin (\alpha)}{P \cos (\alpha)+Q_{1} \sin (\alpha)}
$$




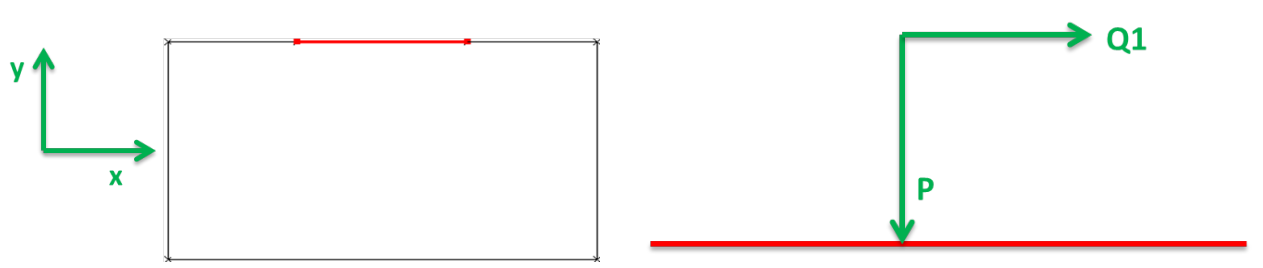

(a)
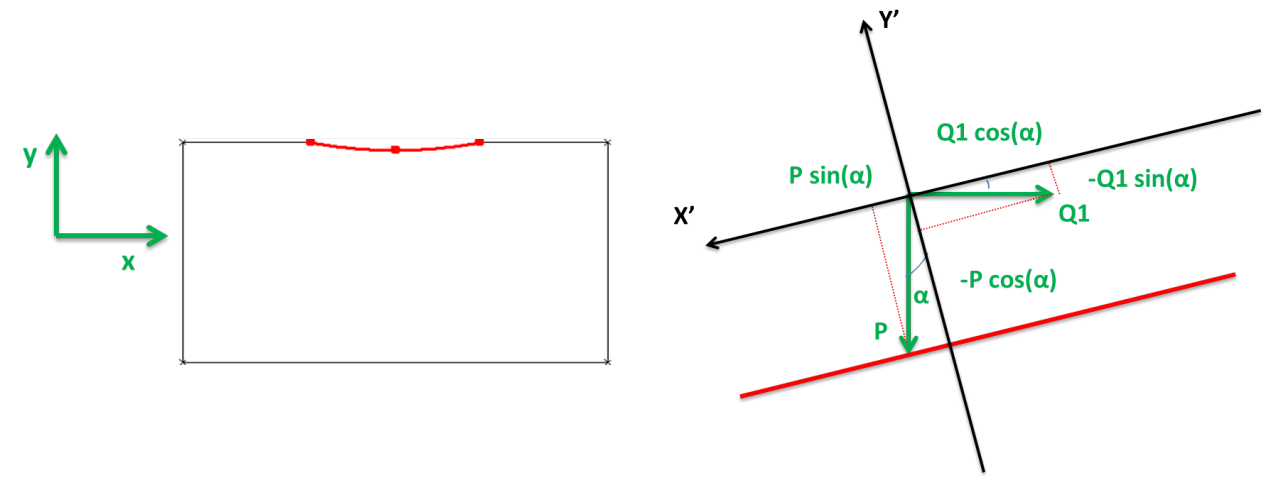

(b)

FIGURE 19: Illustration of the stress on the plane according to the plane geometry. (a) Initial geometry, (b) Worn geometry after $p$ fretting cycles.

where $\alpha$ corresponds to the angle between the initial surface and the worn surface. The tangential load $Q_{1}$ is

$$
Q_{1}=\frac{P(\sin (\alpha)+\mu \cos (\alpha))}{\cos (\alpha)-\mu \sin (\alpha)}
$$

The Apparent Coefficient of friction $\mu_{a p p}$ is defined by the ratio between the intrinsic friction effect and the stress associated with the inclination $\alpha$.

$$
\mu_{\text {app }}=\frac{Q_{1}}{P}=\frac{\mu+\tan (\alpha)}{1-\mu \tan (\alpha)}
$$

The definition of the ACof, (8) leads to the following remarks :

- The value of the ACof depends on the position on the eroded surface. The ACof is equal to the Cof at the center of the contact zone and the extremal values are obtained at the edges of the contact zones.

- Without friction $(\mu=0)$, the ACof corresponds to the force decomposition.

- For a given Cof $\mu$, there is an angle $\alpha=-\arctan (\mu)$ such that the ACof is zero. The contact geometries slide without stress.

- There is a limit angle $\alpha=\arctan (1 / \mu)$ such that there is no sliding. The ACof tends to infinity. 